\title{
BEARING DEFECT DIAGNOSIS AND ACOUSTIC EMISSION
}

\author{
A. Morhain, D. $\mathbf{M b a}^{1}$ \\ ${ }^{1}$ School of Mechanical Engineering, Cranfield University, Cranfield, Beds. MK43 0AL.
}

\begin{abstract}
Acoustic emission (AE) was originally developed for non-destructive testing of static structures, however, over the years its application has been extended to health monitoring of rotating machines and bearings. It offers the advantage of earlier defect detection in comparison to vibration analysis. However, limitations in the successful application of $\mathrm{AE}$ technique for monitoring bearings have been partly due to the difficulty in processing, interpreting and classifying the acquired data.
\end{abstract}

The investigation reported in this paper was centered on the application of standard acoustic emissions (AE) characteristic parameters on a radially loaded bearing. An experimental test-rig was modified such that defects could be seeded onto the inner and outer races of a test bearing. As the test-rig was adapted for this purpose it offered high background acoustic emission noise providing a realistic test for fault diagnosis. In addition to a review of current diagnostic methods for applying $\mathrm{AE}$ to bearing diagnosis, the results of this investigation validated the use of r.m.s, amplitude, energy and AE counts for diagnosis. Furthermore, this study determined the most appropriate threshold level for AE count diagnosis, the first known attempt.

Keywords: Acoustic emissions, bearing defect diagnosis, condition monitoring. 


\section{INTRODUCTION}

Acoustic emissions (AE) are defined as transient elastic waves generated from a rapid release of strain energy caused by a deformation or damage within or on the surface of a material $[1,2,3]$. In this particular investigation, AE's are defined as the transient elastic waves generated by the interaction of two surfaces in relative motion. The interaction of surface asperities and impingement of the bearing rollers over the seeded defect on the outer and inner races will result in the generation of acoustic emission.

\section{ACOUSTIC EMISSION AND BEARING DEFECT DIAGNOSIS}

The formation of subsurface cracks due to the Hertzian contact stress induced by the rolling action of the bearing elements in contact with the inner and outer races, and, the rubbing between damaged mating surfaces within the bearing will generate acoustic emission activity. Catlin [4] reported AE activity from bearing defects were attributed to four main factors including numerous transient and random AE signals associated with bearing defects. Furthermore, it was stated that the signals detected in the AE frequency range represented bearing defects rather than other defects such as imbalance, misalignment, looseness, shaft bending as well as the other major structural component resonance's. In addition, Catlin noted that high frequency AE signatures attenuate rapidly; therefore, if the transducer was placed close to the bearing, it was possible to detect the high frequency content induced mainly by the bearing fault since signatures originating from other machine components are highly attenuated upon reaching the sensor. Roger [5] utilised the AE technique for 
monitoring slow rotating anti-friction slew bearings on cranes employed for gas production and obtained some encouraging results compared to vibration monitoring techniques. Rubbing of the crack faces, grinding of the metal fragments in the bearing and impacts between the rolling elements and the damaged parts in the loaded zone were identified as sources of detectable AE signatures.

Yoshioka and Fujiwara [6,7] have shown that the AE parameters identified bearing defects before they appeared in the vibration acceleration range. In addition, sources of AE generation were identified during fatigue life tests on thrust loaded ball bearings. Hawman et al [8] reinforced Yoshioka's observation that AE provided earlier detection of bearing faults than vibration analysis and noted that diagnosis of defect bearings was accomplished due to modulation of high frequency AE bursts at the outer race defect frequency. Hawman placed the AE receiving sensor directly onto the bearing outer race. The modulation of AE signatures at bearing defect frequencies has also been observed by other researchers [9,10]. In addition, Bagnoli et al [11] investigated demodulation of $\mathrm{AE}$ signatures at the defect rotational frequency (outer race) of a bearing. It was noted that when the defect was absent, the periodicity of the passage of the balls beneath the load could be readily identified by observing the frequency spectrum of demodulated AE signatures, however, it was reported that the AE intensity was less without the defect present. There was no mention of trigger levels employed, load applied on the test bearing, method of attaching the transducers to the rig nor any information on background noise.

The most commonly measured AE parameters for diagnosis are amplitude, r.m.s, energy, counts and events [3]. Counts involve determining the number of times the 
amplitude exceeds a preset voltage (threshold level) in a given time and gives a simple number characteristic of the signal. An AE event consists of a group of counts and signifies a transient wave.

Tandon \& Nakra [12] investigated AE counts and peak amplitudes for an outer race defect using a resonant type transducer. It was concluded that AE counts increased with increasing load and rotational speed. However, it was observed that AE counts could only be used for defect detection when the defect was less than $250 \mu \mathrm{m}$ in diameter, though AE peak amplitude provided an indication of defects irrespective of the defect size. Loads applied ranged from 8 to $50 \%$ of the bearing static load rating. Choudhary et al [13] employed AE for bearing defect identification on various sized bearings and rotational speeds ranging from 500 to $1500 \mathrm{rpm}$. It was observed that $\mathrm{AE}$ counts were low for undamaged bearings, based on a threshold level of 1-volt. In addition, it was observed that AE counts increased with increasing speed for damaged and undamaged bearings whilst an increase in load did not result in any significant changes in AE counts for both damaged and undamaged bearings.

Vibha Bansal et al [14] applied AE as a quality control tool on reconditioned bearings. Bearings were tested at $3 \%$ of the load rating. It was noted that as the load increased there was little increase in the peak-to-peak amplitude level for standard (operational) and reconditioned bearings, however, the peak values of the reconditioned bearing was in some instances five-times that of a new bearing.

Tan [15] used a variation of the standard AE count parameter for diagnosis of different sized ball bearings. In addition to the difficulty of selecting the most 
appropriate threshold level for standard AE counts, Tan sited a couple of other drawbacks with the conventional AE count technique. This included dependence of the count value on the signal frequency. Secondly, it was commented that the count rate was indirectly dependent upon the amplitude of the AE pulses. Tan's variation to the standard AE counts technique involved computing the accumulated area under the amplitude-time curve of the AE waveform over a specified time period. This was accomplished by setting four trigger levels with amplitude multiples of 1, 2, 4 and 8, and calculating the area under the amplitude-time AE waveform. The final count assigned was weighted by the multiple of the amplitude ratio between these levels. It was concluded that the 'new' count rates increased exponentially with increasing defect sizes and increasing rotational speed. The dependence of $\mathrm{AE}$ counts on threshold levels was also noted by Huguet et al [16] during investigations on the use of AE for identifying damage modes in specific materials, in this instance, a trigger level of $10 \%$ of the maximum amplitude was employed.

The acoustic emission technique has also been employed by Miettinen et al [17] to monitor the lubricant condition in rolling element bearing. And successful applications of $\mathrm{AE}$ to bearing diagnosis for extremely slow rotational speeds have been reported $[18,19]$.

It must be noted that the propagation of the acoustic emission is affected by material microstructure, inhomogeneties, geometrical arrangement of free surfaces, loading conditions and number of component interfaces. Almost all research on the application of $\mathrm{AE}$ to bearing defect analysis have been undertaken on experimental test-rigs specifically designed to reduce AE background noise. In addition, a clear 
relationship between r.m.s, amplitude and energy with rotational speed and radial load has been reported, particularly on outer race defects. The successful use of AE counts for bearing diagnosis is dependent on the particular investigation, and, the method of determining the trigger level is at the discretion of the investigator. Moreover, it has been shown that $\mathrm{AE}$ counts are sensitive to the level and grade of lubricant within the bearing, adding to the complexity of this measure. For these reasons, the investigation presented in this paper intends to validate the use of r.m.s, amplitude, energy and AE counts for diagnosis and to determine a method for selecting the most appropriate threshold level for AE counts.

\section{EXPERIMENTAL EQUIPMENT}

A test rig was designed to simulate early stage of bearing defects, see figure 1 . The rig consisted of a motor/gear box unit that providing a rotational speed range of between 10 to $4000 \mathrm{rpm}$. Two aligning support bearings, a rubber coupling and a larger support bearing, type FAFNIRDRN-A9598 (internal bore diameter of $50 \mathrm{~mm}$ ) was employed. 


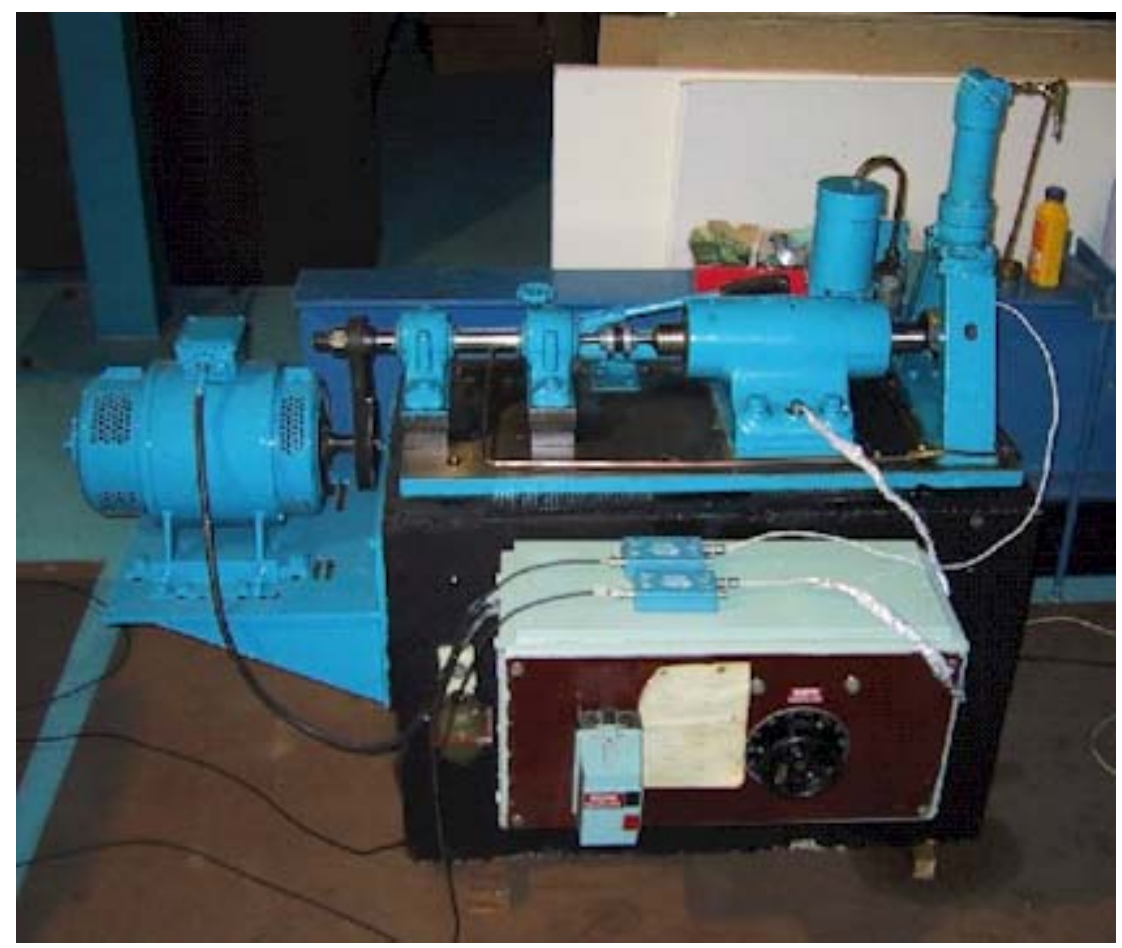

\section{Figure $1 \quad$ Bearing test-rig; Insert shows close-up of test bearing}

The test bearing investigated was a split Cooper spherical roller, type 01C/40GR. This type of bearing was chosen owing to its ability to be disassembled without removing slave bearings, thereby allowing the test bearing to be regularly inspected throughout the test programme. Furthermore, it allowed assembly of the defective components with minimal disruption to the test-rig. A radial load was applied to the top of the bearing via a hydraulic cylinder ram supported by an ' $\mathrm{H}$ ' frame. All attempts were undertaken to ensure the amount of grease within the bearing remained the same. It must be noted that for all tests and simulations, the receiving transducer was cemented onto the test bearing housing, see figure 2 . 
Characteristics of the test bearing (Split Cooper, type 01C/40GR) were:

- Internal (bore) diameter, $40 \mathrm{~mm}$

- External diameter, $84 \mathrm{~mm}$

- Diameter of roller, $11.9 \mathrm{~mm}$

- Number of rollers, 10

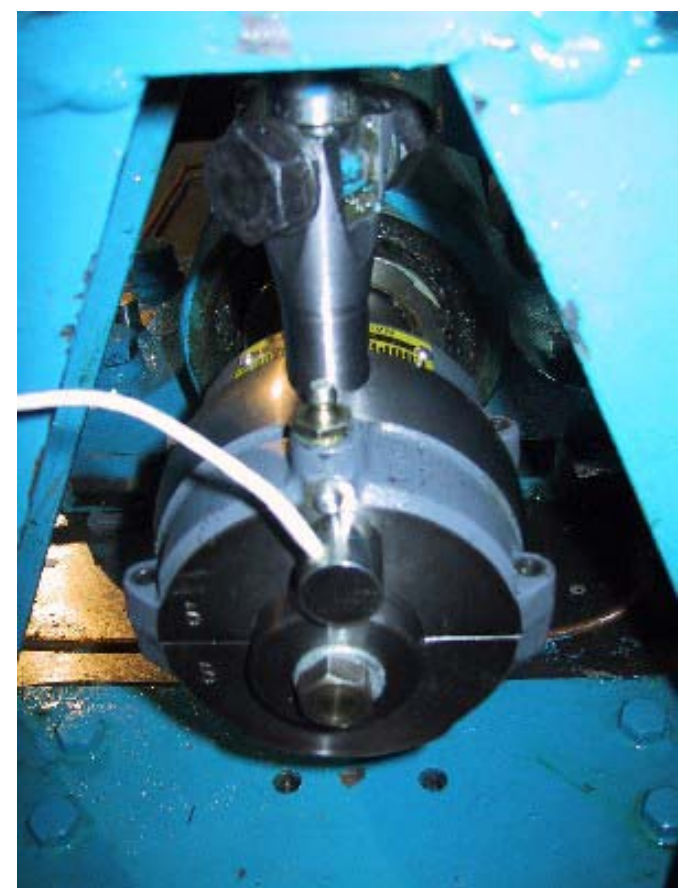

Figure 2 Position of $\mathrm{AE}$ receiving sensor on test bearing

\section{DATA ACQUISITION SYSTEM}

A piezoelectric type sensor (Physical Acoustic Corporation type WD) with an operating frequency range of $100 \mathrm{kHz}-1000 \mathrm{kHz}$ was employed. A schematic diagram of the acquisition system is illustrated in figure 3. 


\section{COMPUTER Post processing}

\section{Figure 3 Schematic diagram of acquisition system}

Pre-amplification ranged from 40 to $60 \mathrm{~dB}$ (PAC type 1220A, bandwidth between 20 $\mathrm{kHz}$ and 1.2 MHz). The signal output from the pre-amplifier was connected (i.e. via $\mathrm{BNC} /$ coaxial cable) directly to a commercial data acquisition card within a Pentium host PC. This AEDSP acquisition card provided up to $8 \mathrm{MHz}$ sampling rate and incorporated 16-bit precision giving a dynamic range of more than $85 \mathrm{~dB}$. Prior to the analog-to-digital converter (ADC) anti-aliasing filters were employed. A total of 33,000 data points were recorded per acquisition (data file) at a sampling rate of 4MHz. One hundred (100) data files were recorded for each simulated case, providing over 0.8 seconds of data per fault simulation. This was equivalent to 8 -revolutions of data at $600 \mathrm{rpm} ; 20$-revolutions at $1500 \mathrm{rpm}$ and 40 -revolutions at $3000 \mathrm{rpm}$. A trigger level of $31 \mathrm{mV}$ was employed, this was not set above background noise conditions so that realistic diagnostic conditions were replicated, in effect this trigger level was equivalent to a 'free run' of the acquisition system. The procedure for recording data simply involved arming the acquisition system at random intervals over a 15 -minute period for each simulation. It was thought this would provide a good test on the robustness of specific AE characteristic parameters to diagnosis of operational bearings. 


\section{SIGNAL PROCESSING}

The AE parameters measured for diagnosis in this particular investigation were amplitude, r.m.s, energy and AE counts. The energy was computed with the trapezoidal numerical integration. AE counts at varying percentages of a defined amplitude were calculated.

\section{EXPERIMENTAL PROCEDURE}

\subsection{Attenuation test by breaking leads}

Prior to defect simulations, attenuation tests were undertaken on the test-rig to determine its characteristics. This involved pressing lead, $0.5 \mathrm{~mm} 2 \mathrm{H}$, obliquely against the surface at predetermined positions on the bearing. Four positions were identified; the inner and outer races, the rolling elements and the bearing casing adjacent to the receiving transducer, see figure 4. This test is widely known as the Nielson source test. Due to the simplicity and repeatability in generating AE signals it was used for evaluating attenuation characteristics across the bearing. 


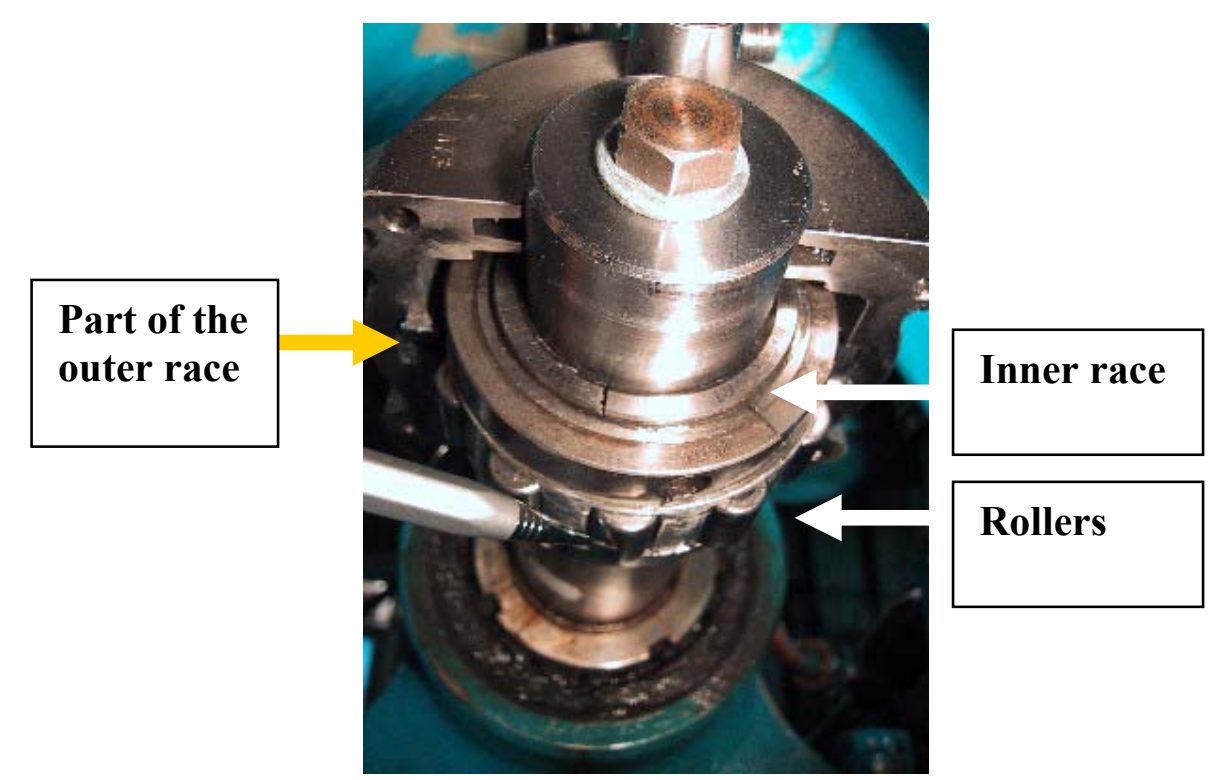

Figure 4 Determining attenuation characteristics across the bearing

Five readings at each position were recorded and averaged, see appendix A. During attenuation tests all attempts were undertaken to ensure direct contact between the inner race, roller, outer race and the bearing casing. This was accomplished by positioning a roller at top-dead-center in direct path with the load. The reference used for attenuation calculations was the AE input adjacent to the sensor on the bearing casing $\left(\mathrm{P}_{\mathrm{ref}}\right)$ and the relative attenuation was computed by:

$$
d B=20 * \log \left(P_{i} / \mathrm{P}_{\mathrm{ref}}\right)_{i=A E \text { input on bearing elements }}
$$

The relative attenuation of $\mathrm{AE}$ signatures generated on the inner race was approximately $12 \mathrm{~dB}$ and $3 \mathrm{~dB}$, in terms of r.m.s and maximum amplitude respectively. Rates of approximately $30 \mathrm{~dB}$ and $16 \mathrm{~dB}$ were observed with AE signatures generated on the roller, whilst attenuation rates of $4 \mathrm{~dB}$ and $0 \mathrm{~dB}$ were also noted for $\mathrm{AE}$ inputs on the outer race, see figure 5. 


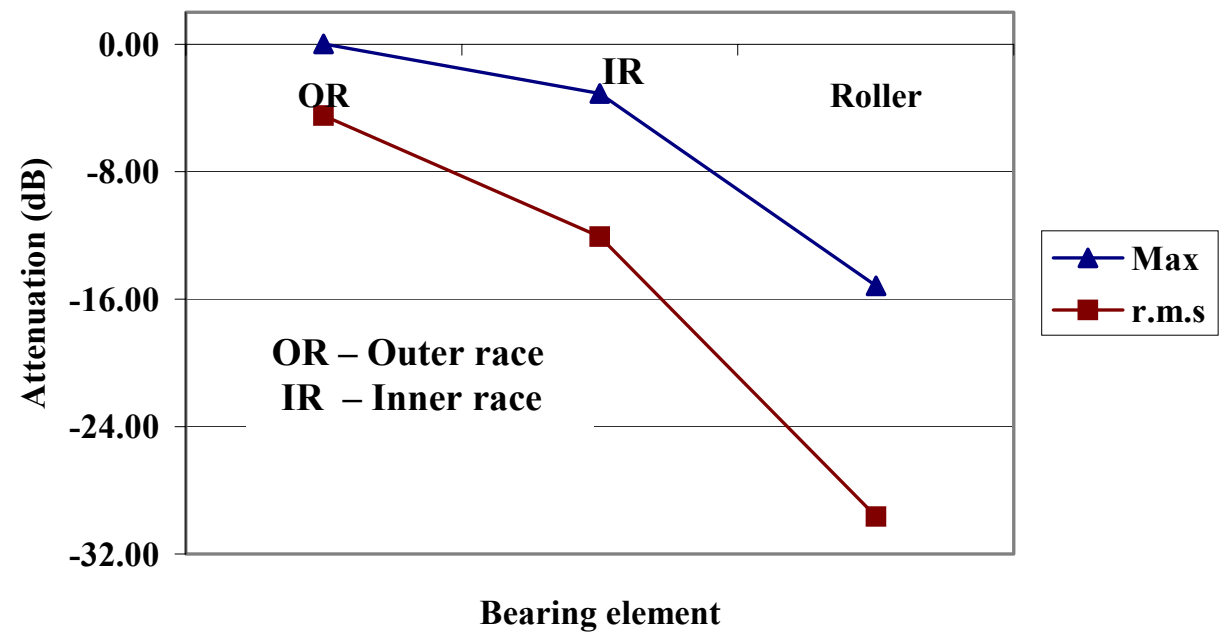

Figure 5 Relative attenuation of bearing elements at $0 \mathrm{KN}$

It was noted that increasing the load during attenuation tests resulted in a decrease in maximum amplitude and r.m.s values of AE signatures from the inner race, see figure 6. This was attributed to the position of the roller at top-dead-center and the unrestricted rotational movement of the bearing during attenuation tests. As such, when a load was applied at top-dead-center, the roller directly in the path of the load will be displaced from its initial position, thereby altering the direct transmission path. Due to the assembly and arrangement of the test bearing during these tests, see figure 4, the AE source input on the roller was at bottom-dead-center where the section of bearing was unloaded. A clearance between the roller and the races will exist at this position and explains the marked difference in attenuation of the roller in comparison to the inner and outer races. If however, it was possible to seed an AE source on the roller at top-dead-center within the loaded zone, it would be expected that the attenuation rate would be between that of the inner and outer races, as long as the roller remained at this position irrespective of the loading. In contrast, loading had no effect on the attenuation characteristics of the outer race. 


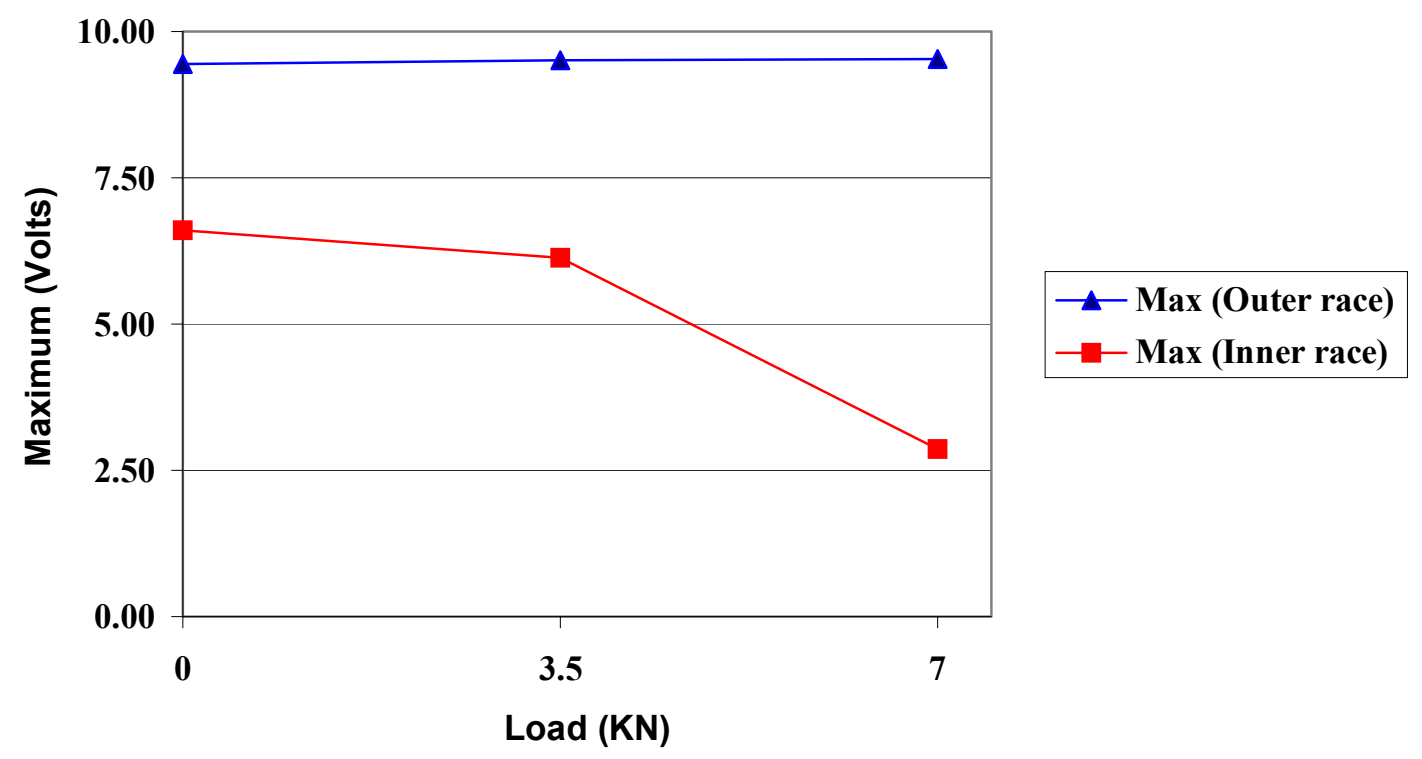

Figure 6 Effect of the load on attenuation of the test bearing

\subsection{Running test}

Two types of defects were seeded on the inner and outer races. The seeded fault was a surface line defect that was accomplished with an engraving machine. The nominal width, depth and length of the line defect on the outer and inner race was measured at $1 \mathrm{~mm}, 75 \mu \mathrm{m}$ and $5 \mathrm{~mm}$ for a 'small defect', while the 'large defect' had a length of approximately $15 \mathrm{~mm}$, see figures 7 and 8 . The test-rig was operated at three different rotational speeds; $600 \mathrm{rpm}, 1500 \mathrm{rpm}$ and $3000 \mathrm{rpm}$. For each rotational speed three load cases were considered: $0 \mathrm{kN}, 2.4 \mathrm{kN}$ and $4.8 \mathrm{kN}$, and for every test condition a total of 100 data files were recorded. Prior to seeding defects the test-rig was operated to provide an indication of background noise levels. For background noise measurements the rig was operated at up to $4000 \mathrm{rpm}$ at $0 \mathrm{KN}$. To simulate realistic diagnostic conditions, the timing of data acquisition was selected randomly within a 15 -minute test period. It was felt that this approach was representative of the likely method to be employed on 
operational units. Maximum amplitude, energy and r.m.s values detailed were determined over the complete set of one hundred data files per simulation. AE counts detailed are in effect an accumulation of counts of one hundred data files.

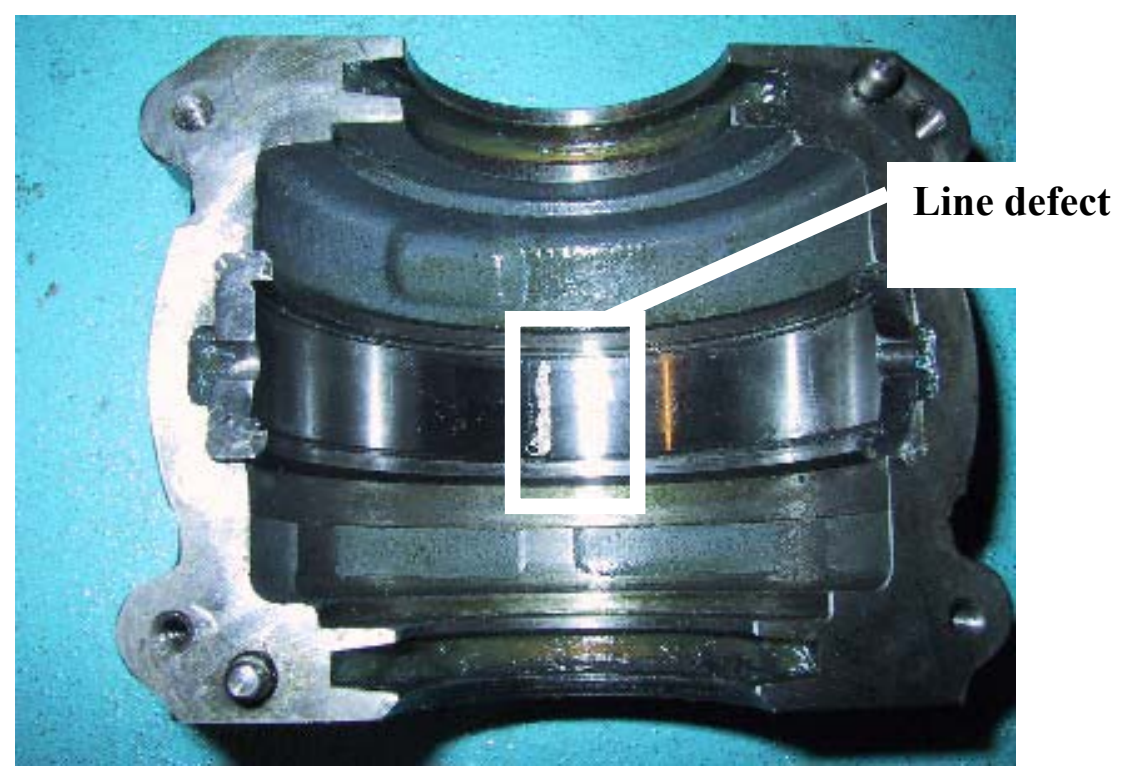

\section{Figure $7 \quad$ Seeded line defect on outer race}
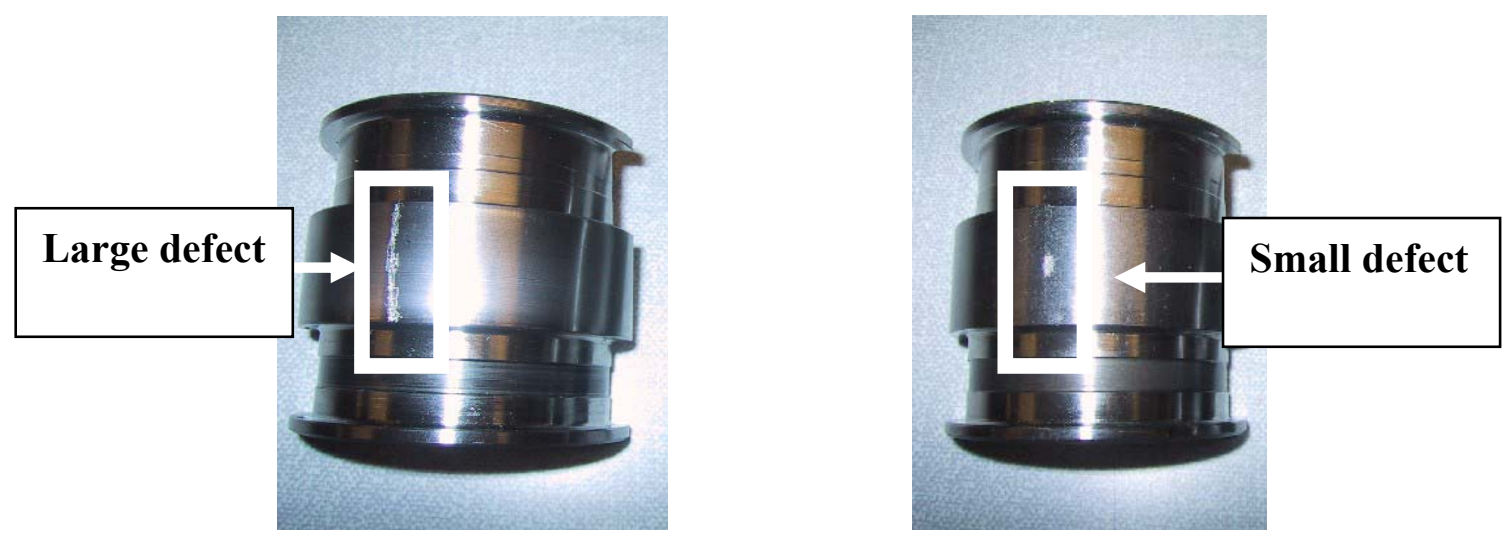

Figure 8 Seeded 'small' and 'large' defects on the inner race 


\section{EXPERIMENTAL RESULTS}

It must be noted that at the higher speeds (3000 and $4000 \mathrm{rpm})$, pre-amplification was reduced to $40 \mathrm{~dB}$. All the results presented are comparative at $60 \mathrm{~dB}$, which implied that a multiplication factor of 10 was applied to all data captured at $40 \mathrm{~dB}$. Prior to analysis all AE signatures were passed through a $5^{\text {th }}$ order median filter [20] to eliminate any spurious electrical spikes. AE characteristic parameters extracted included; r.m.s, peak amplitude, energy and counts[3].

\subsection{Background noise}

A collection of $\mathrm{AE}$ time signatures for background noise is shown in figures 9 to 11. Figures 10 and 11 are close-up AE signatures of figure 9, primarily to provide evidence that the spiky part of the AE signatures is not attributed to spurious electronic noise. 


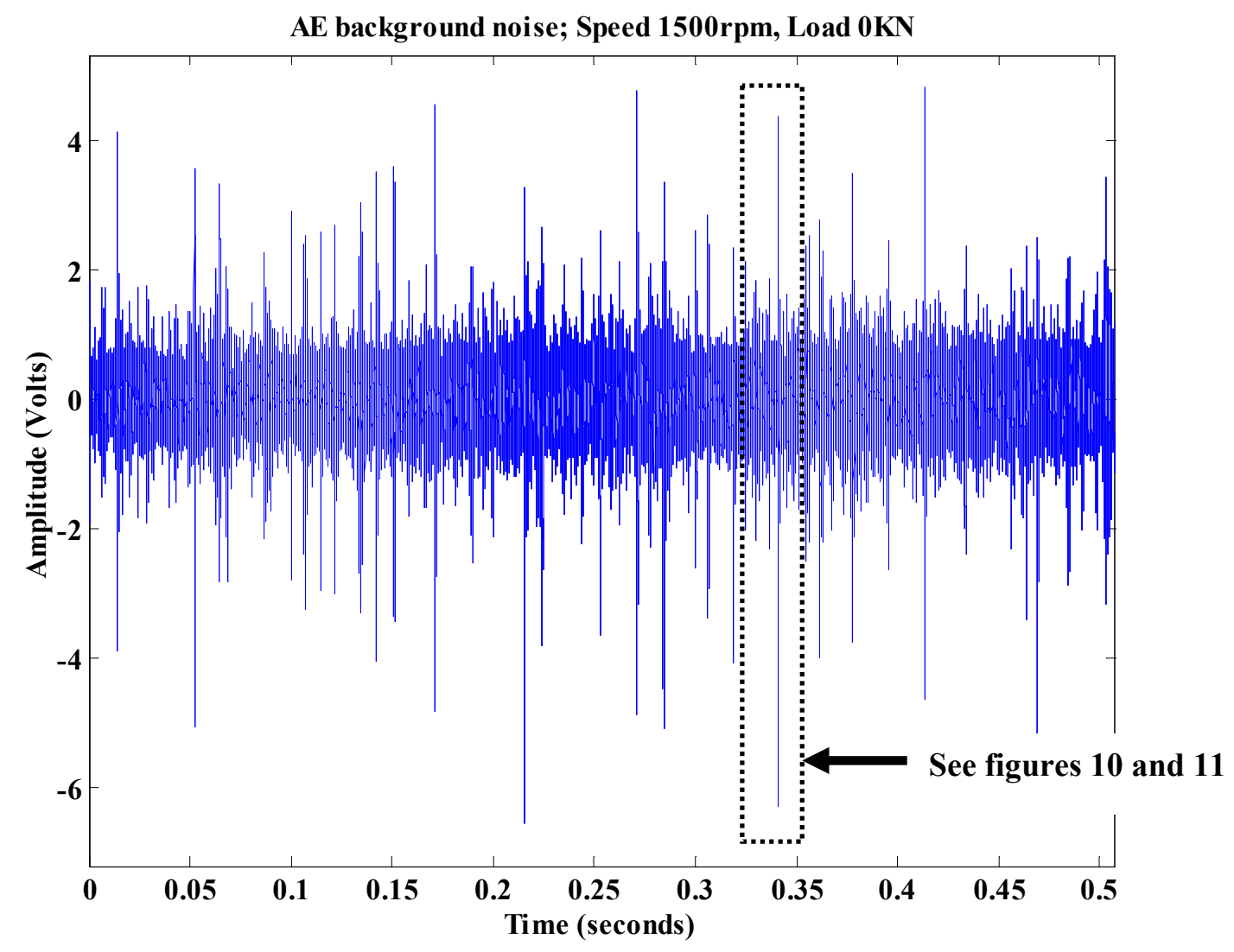

Figure 9 Typical background noise AE signature; Speed 1500rpm, load 0KN. 


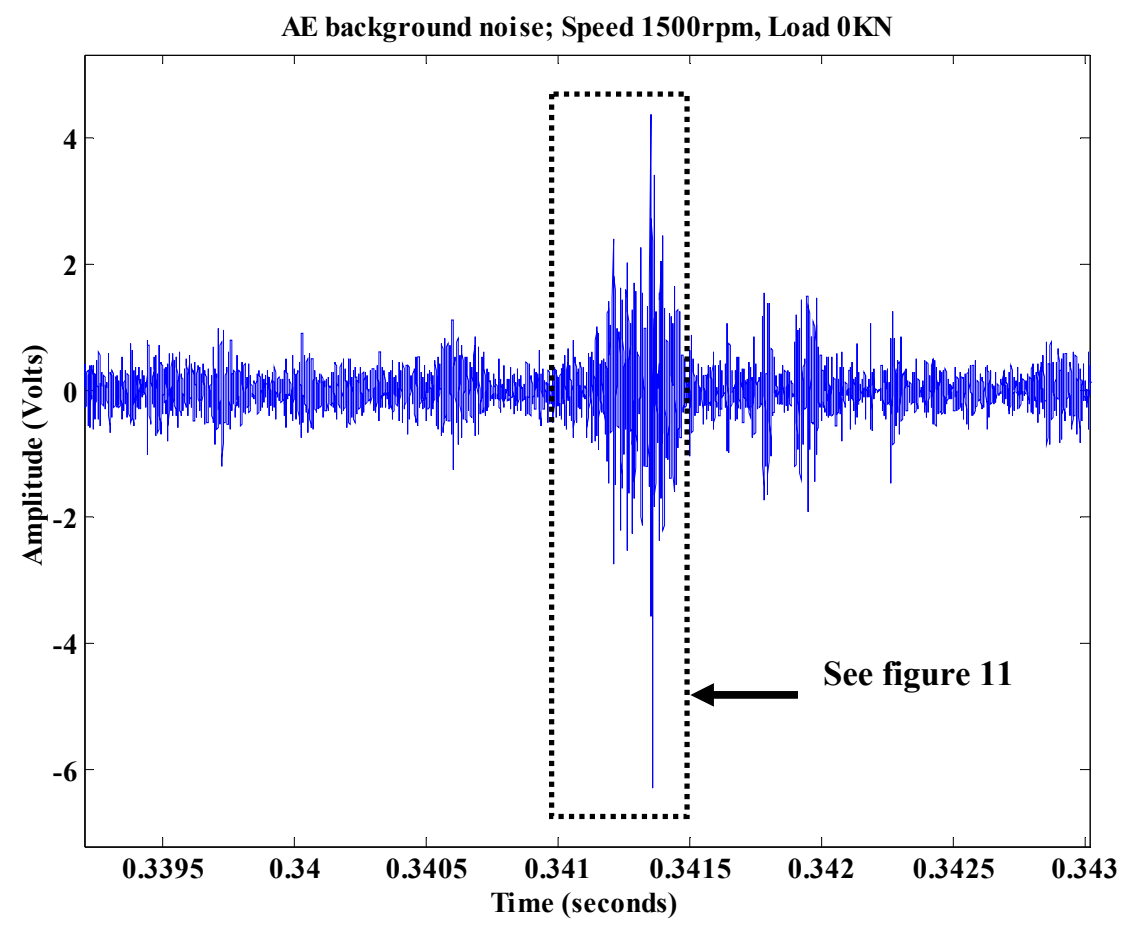

Figure 10 Typical background noise AE signature; Speed 1500rpm, load 0KN (Zoom from figure 9).

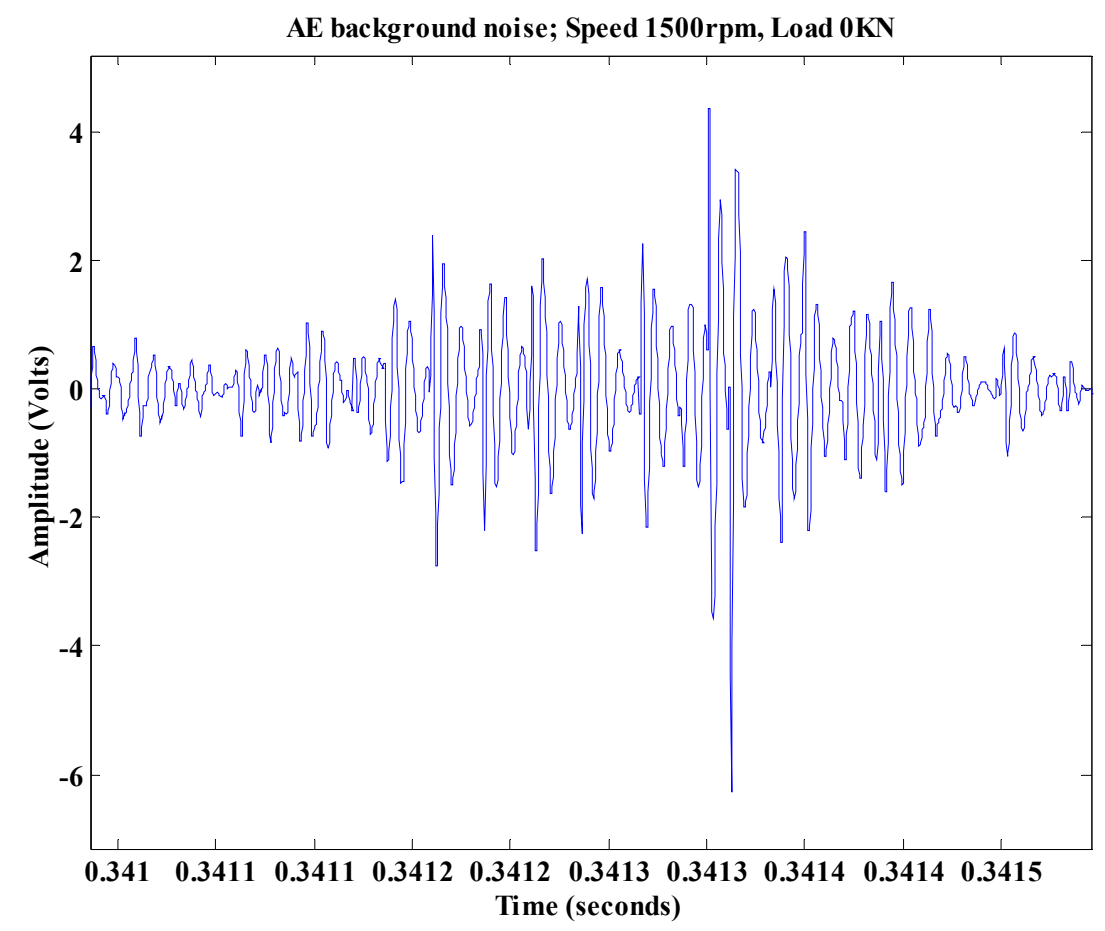

Figure 11 Typical background noise AE signature; Speed 1500rpm, load 0KN (Zoom from figure 10). 
The following format was employed for labeling all AE data presented:

L0; L2; L4; L - load; 0 load value - 0KN; 2 - 2.4KN; $4-4.8 \mathrm{KN}$

'N6L0'; N - Noise; 6 - speed at 600 rpm; L - load; 0 load value - 0KN

'Si30'; S - Small defect; i - inner race; 30 speed - 3000 rpm.

'O6L4'; Outer race defect at 600rpm and 4.8KN

'I15L2'; Inner race defect at 1500rpm and $2.4 \mathrm{KN}$

'Li15L2'; Large inner race defect at 1500rpm and 2.4KN.

Table 1 details AE values extracted for background noise at the three different speeds whilst figure 12 highlights the differences in r.m.s values.

Table 1 AE parameters for background noise

\begin{tabular}{|c|c|c|c|}
\multicolumn{1}{c|}{ Test condition } & N6L0 & N15L0 & N40L0 \\
\hline r.m.s (volts) & 0.06 & 0.37 & 0.66 \\
\hline Max. amplitude (V) & 1.71 & 6.55 & 18.02 \\
\hline Energy (Vseconds) & 0.02 & 0.14 & 0.23 \\
\hline
\end{tabular}

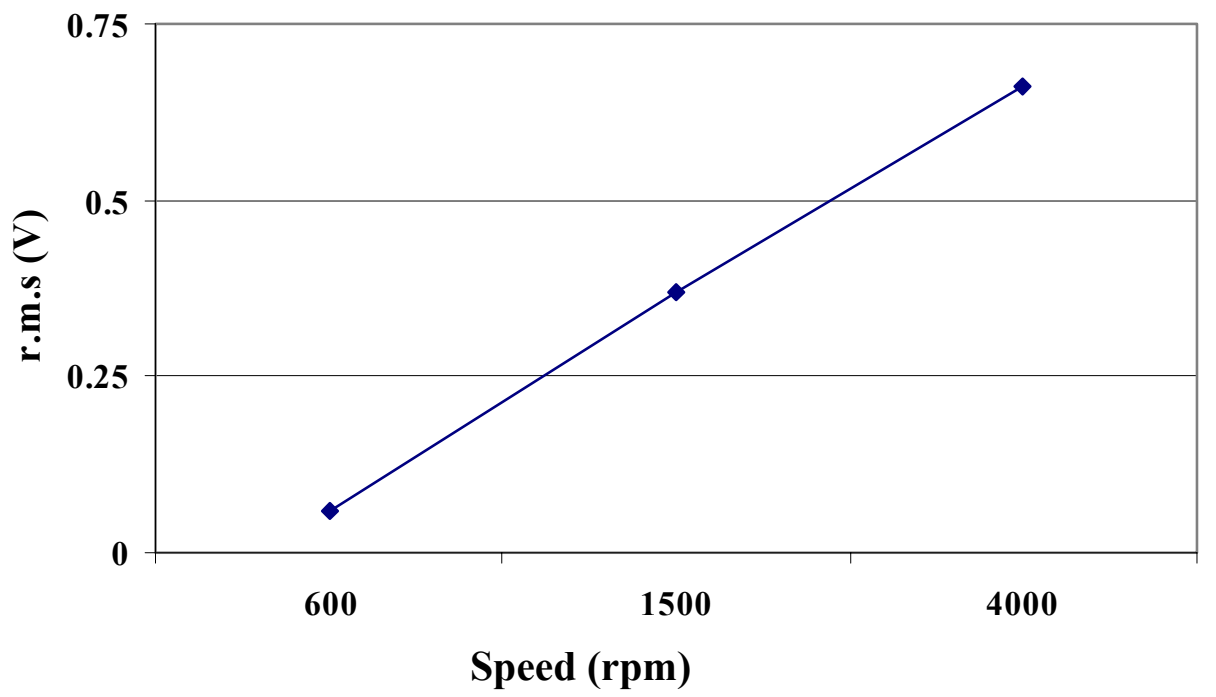

Figure 12 r.m.s of background noise at $0 \mathrm{KN}$ for varying speed conditions 
In order to access the relationship between the threshold level and AE counts, and to determine the most appropriative threshold level, five threshold values were calculated at varying percentages of the maximum amplitude for the lowest background noise case considered, $600 \mathrm{rpm}$ and 0KN (maximum amplitude of 1.7 volts). The percentage values selected were $10 \%, 30 \%, 50 \%, 70 \%$ and $90 \%$ with corresponding threshold values of $0.17,0.5,0.85,1.2$ and 1.5 volts respectively. The reason for selecting these specific values was it offered a wide range of values, particularly useful as the investigators hoped to ascertain and determine the influence of threshold value on $\mathrm{AE}$ count results. Usually determining the threshold levels have been at the discretion of the investigator and in most cases, the values were probably selected on intuition and/or experience on the particular test-rig or machine. Results of AE counts for background noise at specified threshold levels are presented in table 3 and figure 13. A direct relationship between speed and AE count was observed.

Table 3 AE counts for background noise

\begin{tabular}{|c|c|c|c|c|c|}
\multicolumn{1}{c|}{ Threshold } & $\mathbf{0 . 1 7 V}$ & $\mathbf{0 . 5 V}$ & $\mathbf{0 . 8 5 V}$ & $\mathbf{1 . 2 V}$ & $\mathbf{1 . 5 V}$ \\
\hline Condition & & & & & \\
\hline N6L0 & 1757 & 61 & 8 & 2 & 1 \\
\hline N15L0 & 60732 & 19595 & 4767 & 1643 & 899 \\
\hline N40L0 & 72855 & 38675 & 14988 & 6012 & 3327 \\
\hline
\end{tabular}




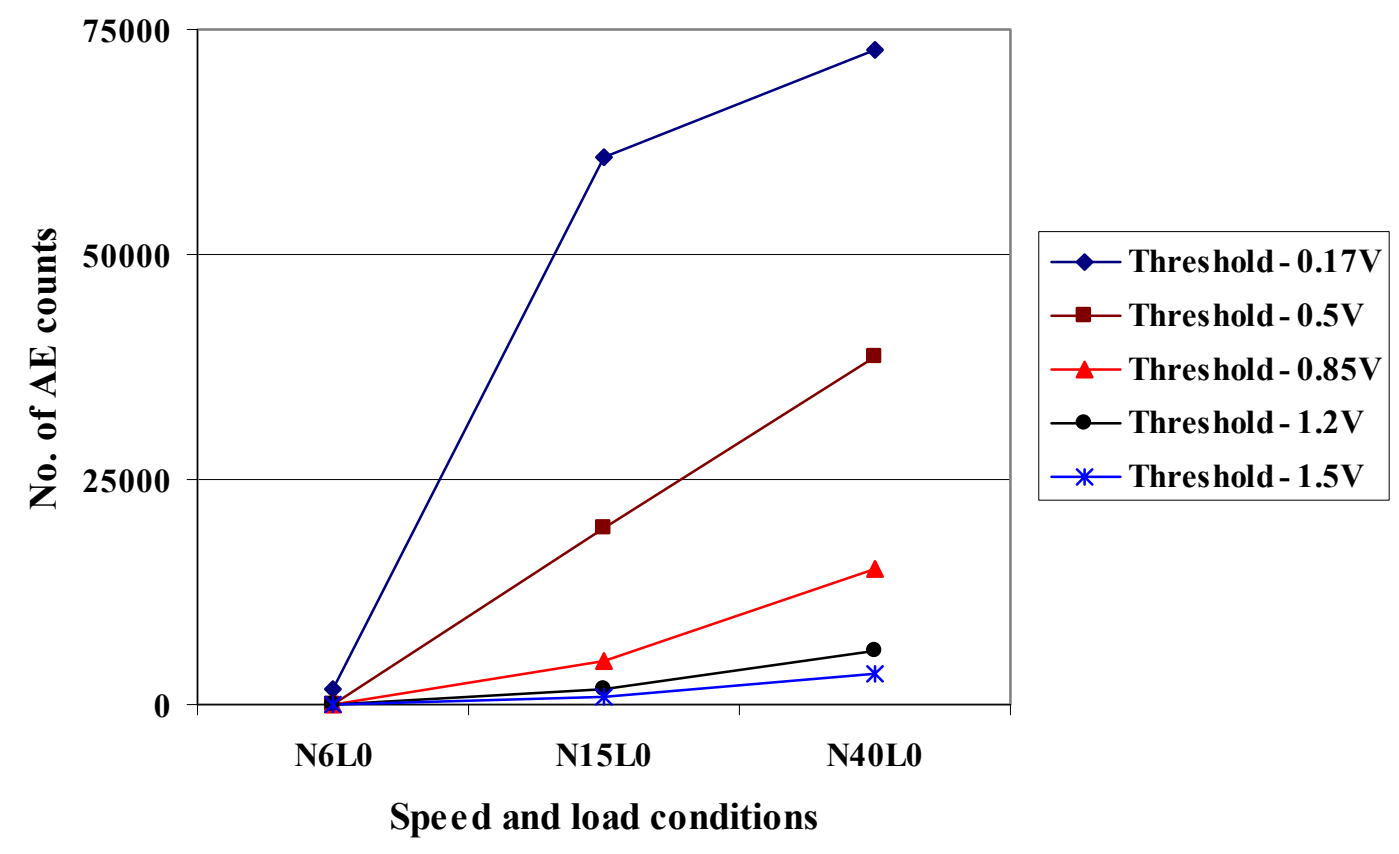

Figure 13 AE counts for background noise as a function of threshold levels

\subsection{Results of AE amplitude, energy and r.m.s for defect simulation}

A collection of typical AE time signatures for an outer race defect is shown in figure 14. 


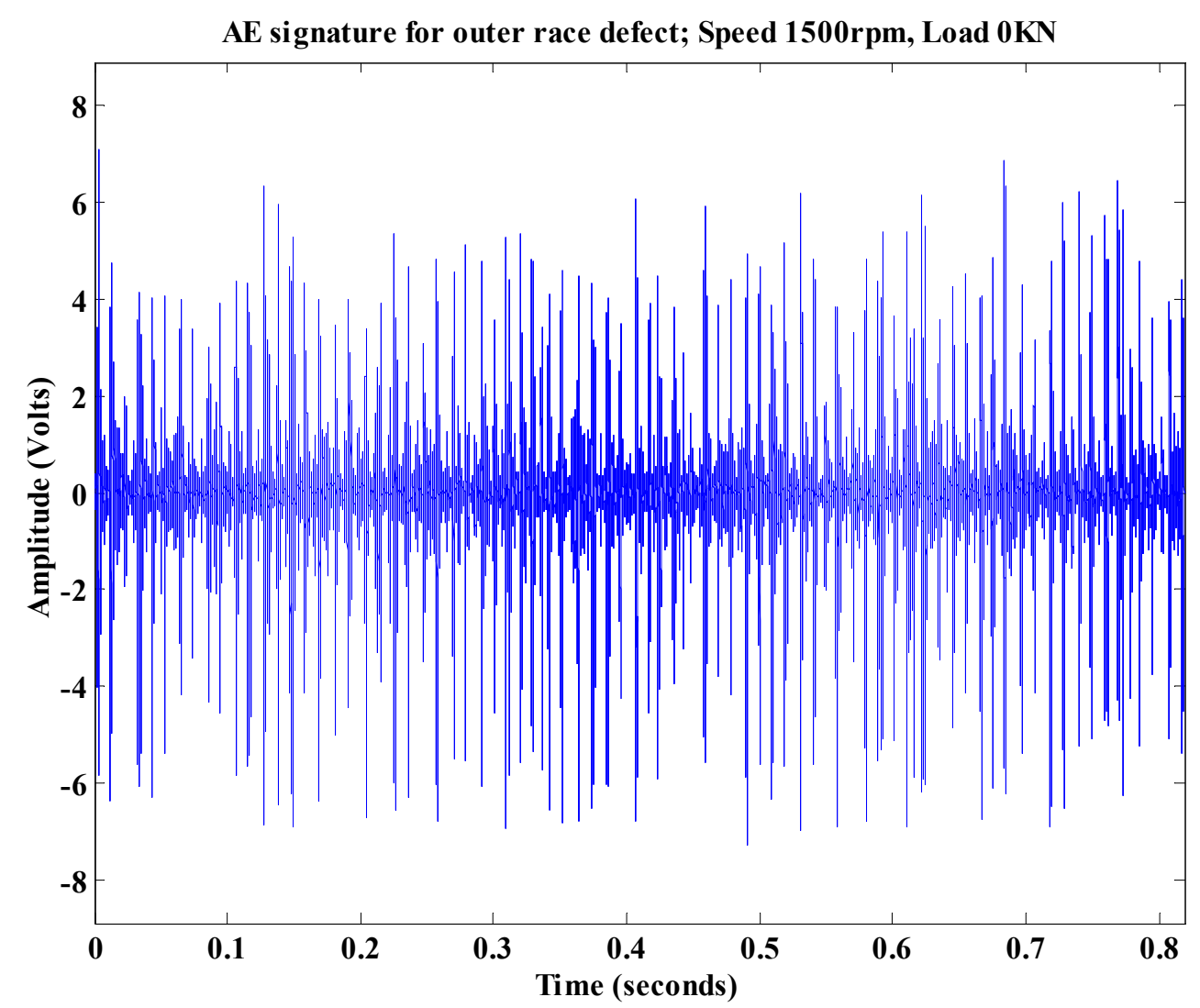

Figure 14 Typical outer race defect AE signature; Speed 1500rpm, load 0KN.

Appendix B, details maximum amplitude, r.m.s and energy values of $\mathrm{AE}$ signatures associated with seeded defects at varying speed and load conditions. Typically, AE r.m.s and energy values increased with increasing load, speed and defect size. Figures 15 and 16 illustrate the relationship between r.m.s and outer and inner race defects. 


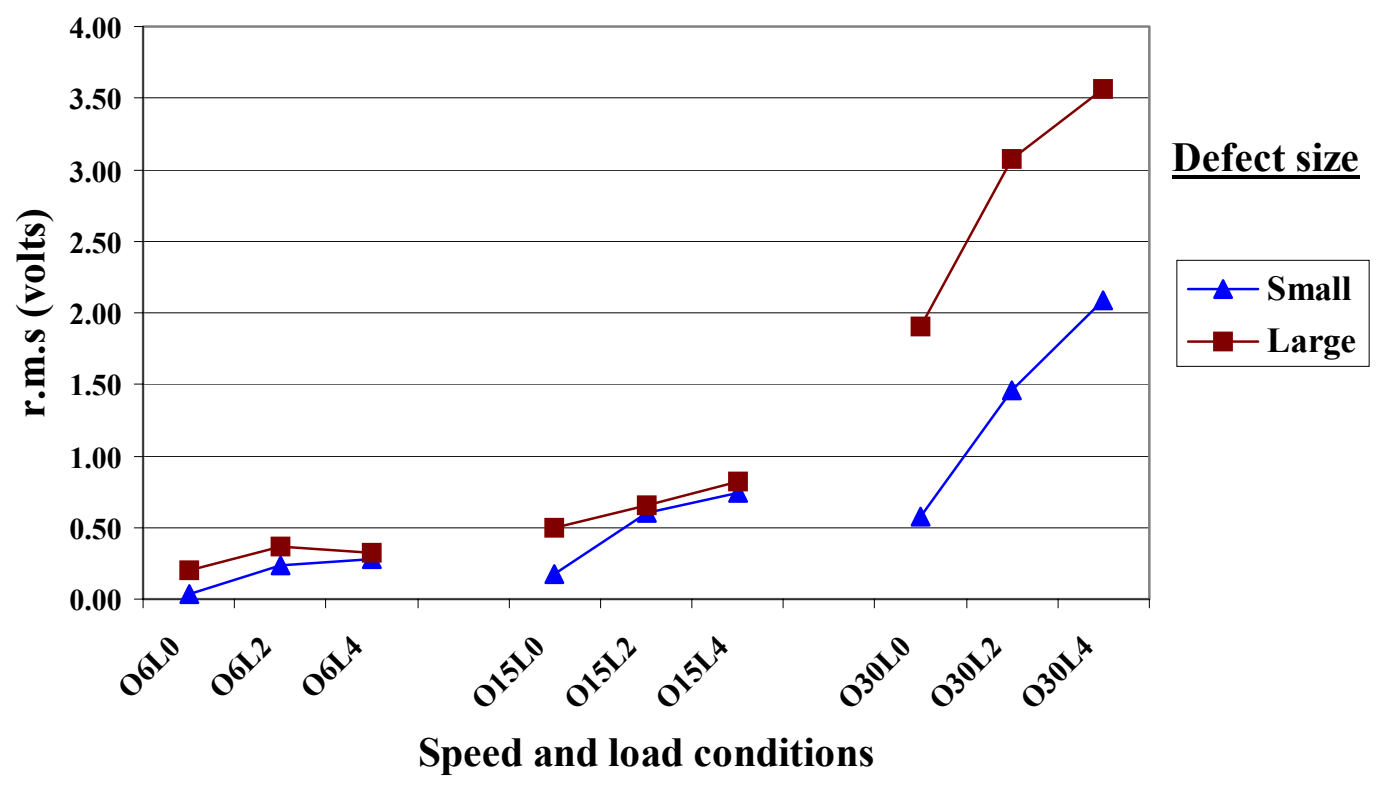

Figure 15 r.m.s values for outer race defects

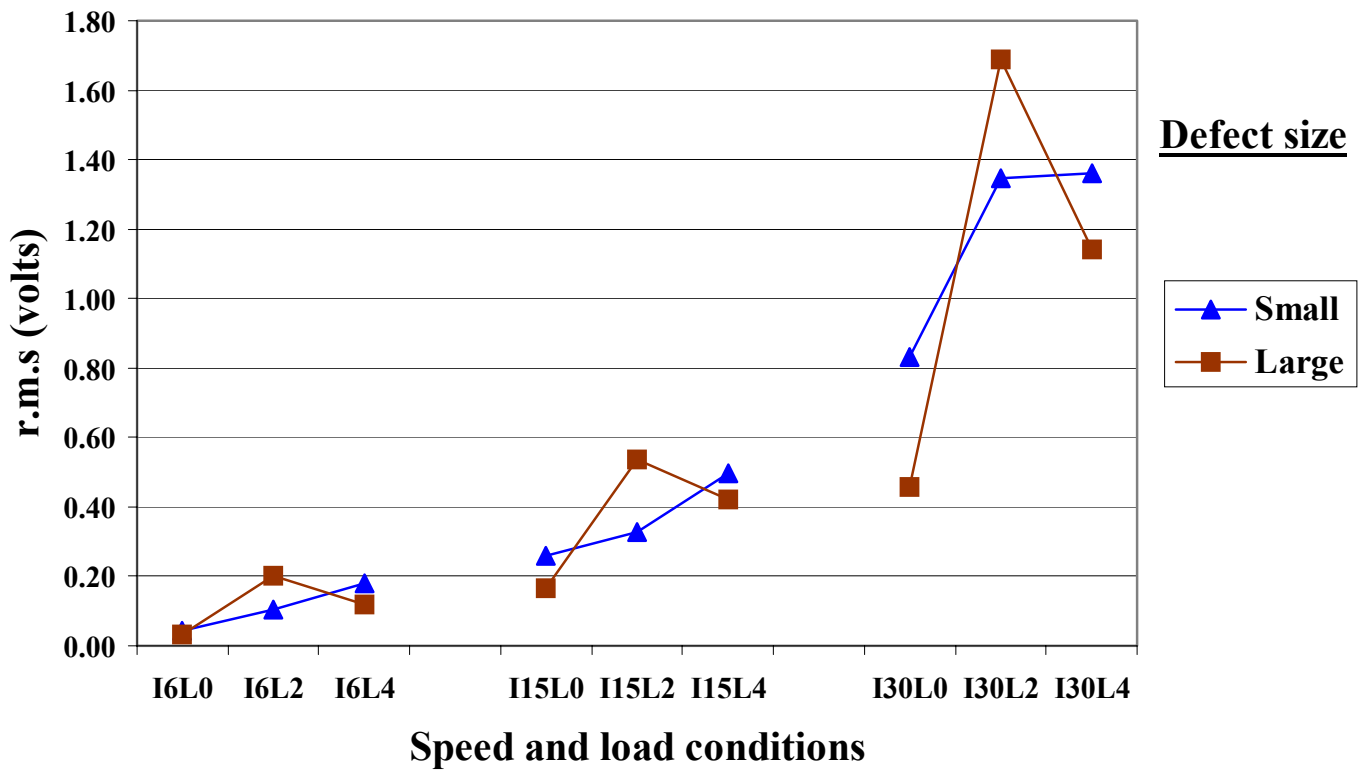

Figure $16 \quad$ r.m.s values for inner race defects

For all outer race defects an increase in r.m.s was observed for increasing speed and defect size. This trend also applied to 'small' inner race effects, however, for 'large' inner race defects, at a load of $4.8 \mathrm{KN}$, the r.m.s values decreased relative to a load of $2.4 \mathrm{KN}$, see figure 16 . It should be noted that the r.m.s values at 
$4.8 \mathrm{KN}$ were higher than at $0 \mathrm{KN}$. Comparisons of AE r.m.s values showed an increase for outer race defects in comparison to inner race defects, see figure 17. This can be attributed to increased attenuation experienced by signatures from the inner race, as vindicated in the attenuation tests reported.

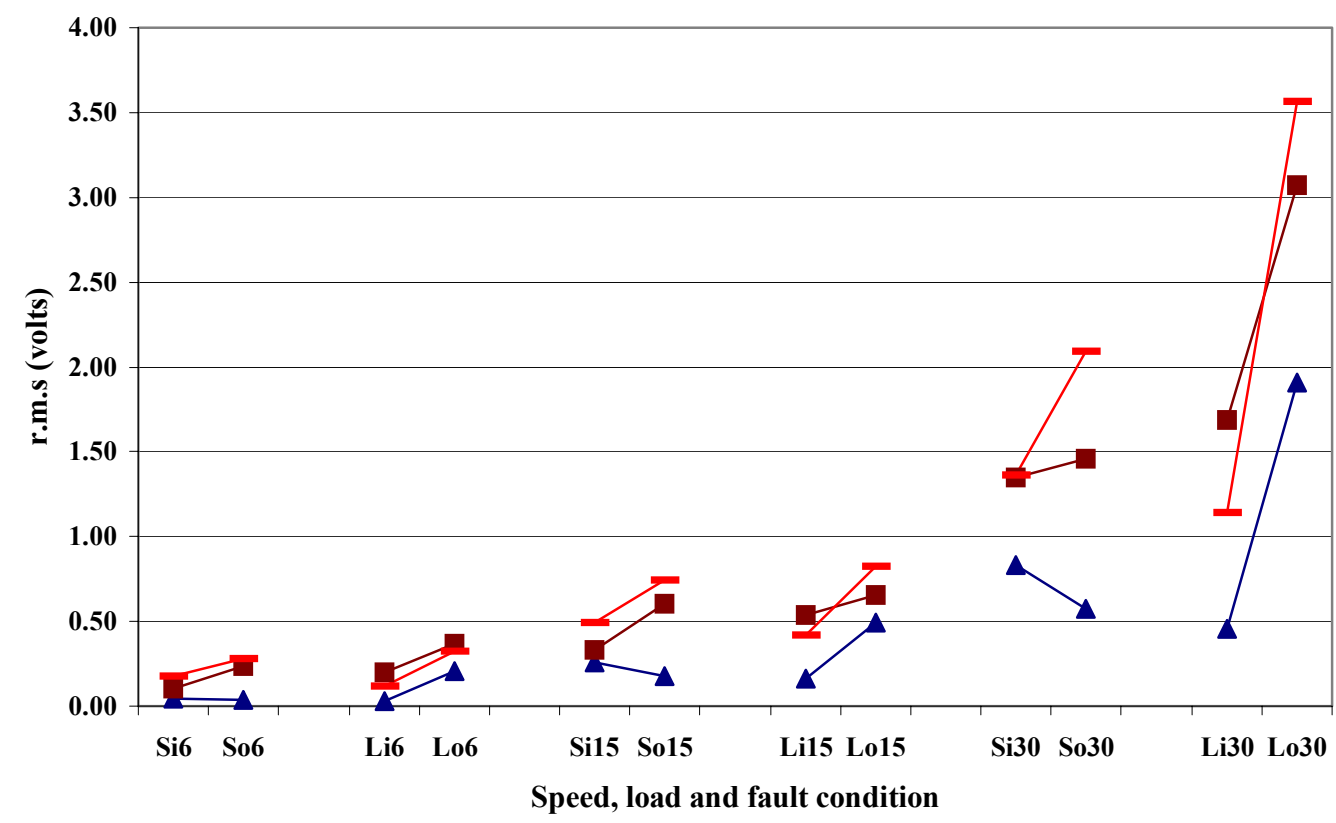

Figure 17 r.m.s values for inner and outer race defects as a function of load, speed and defect size

Figure 18 depicts the relationship between r.m.s values and defect size. For outer race defects there was an increase in r.m.s with defect size, irrespective of the applied load, however, for inner race defects this was not observed for all cases considered, see figure 18 . 


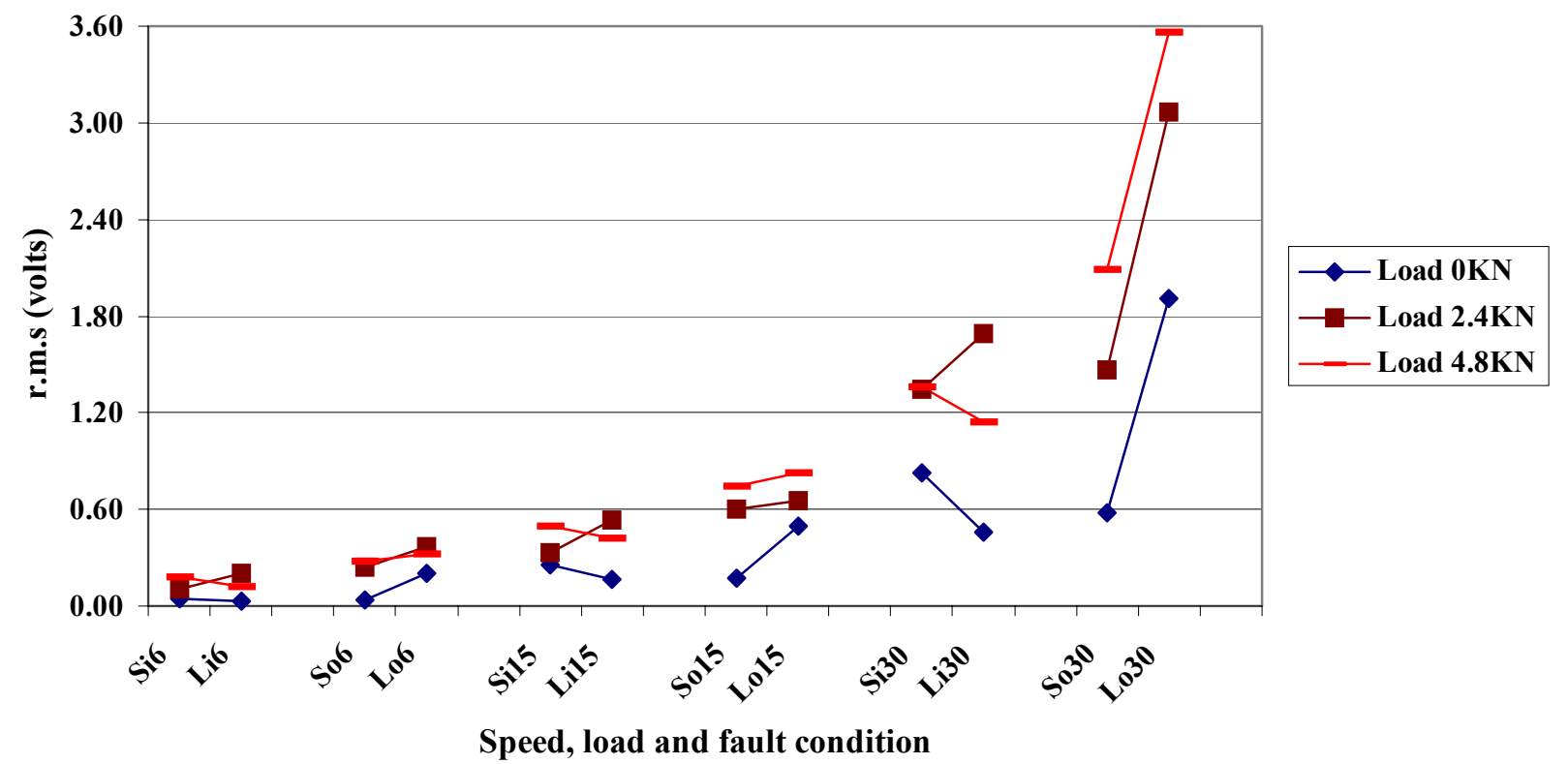

Figure 18 r.m.s values for inner and outer race defects as a function of load, speed and defect size

The results presented thus far are in agreement with several researchers $[7,12,13,14$, 15] and forms the basis from which to investigate the influence of threshold levels on AE counts and determine an appropriate threshold.

\subsection{Results of AE counts with varying loads}

Results of counts for all defects at varying speeds and loads can be viewed in appendix C. Figures 19 and 20 illustrate the relationship between AE counts and defect size on the inner and outer races at varying load cases and threshold levels. 


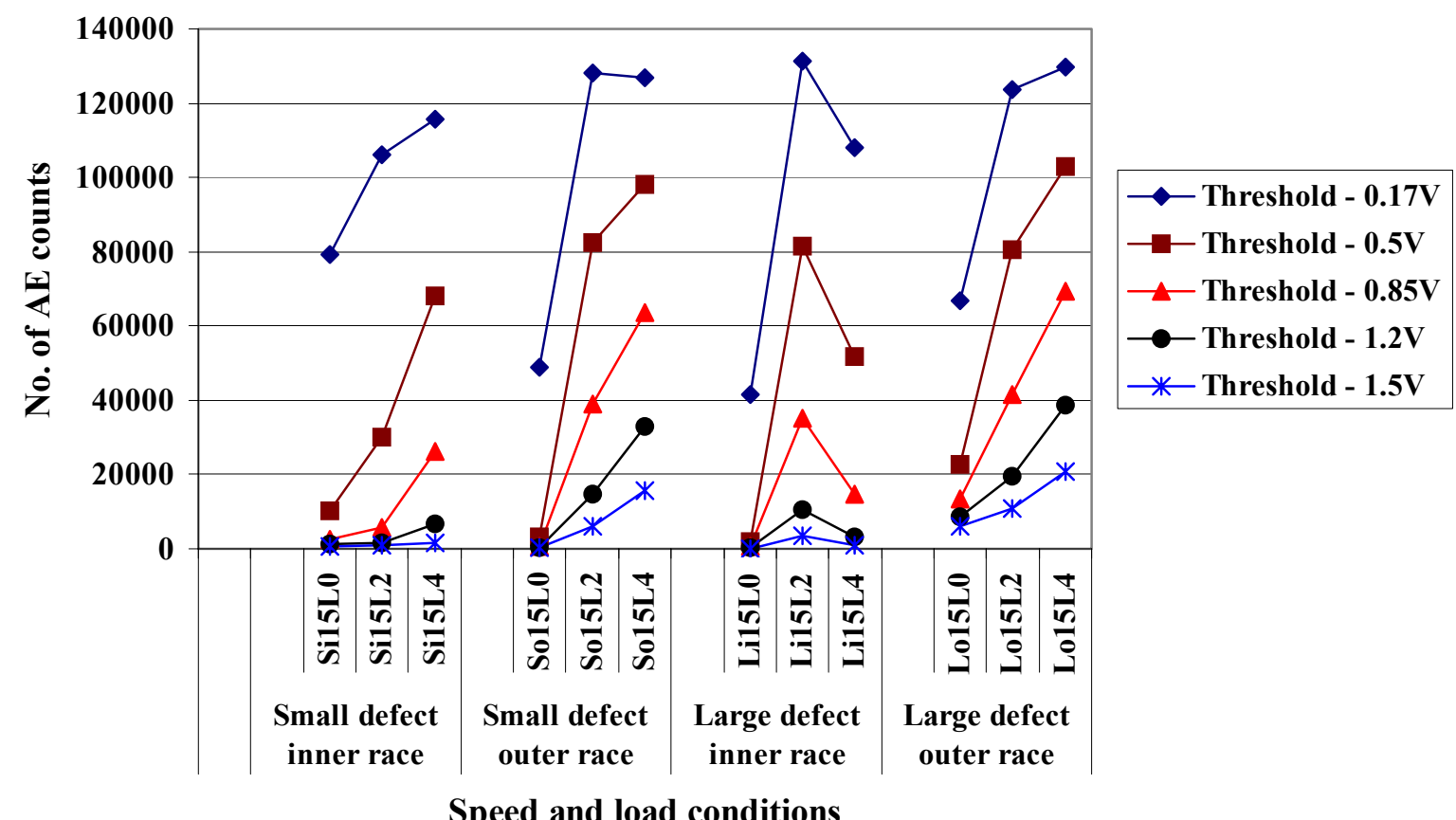

Figures 19 Number of AE counts for varying defects at $1500 \mathrm{rpm}$

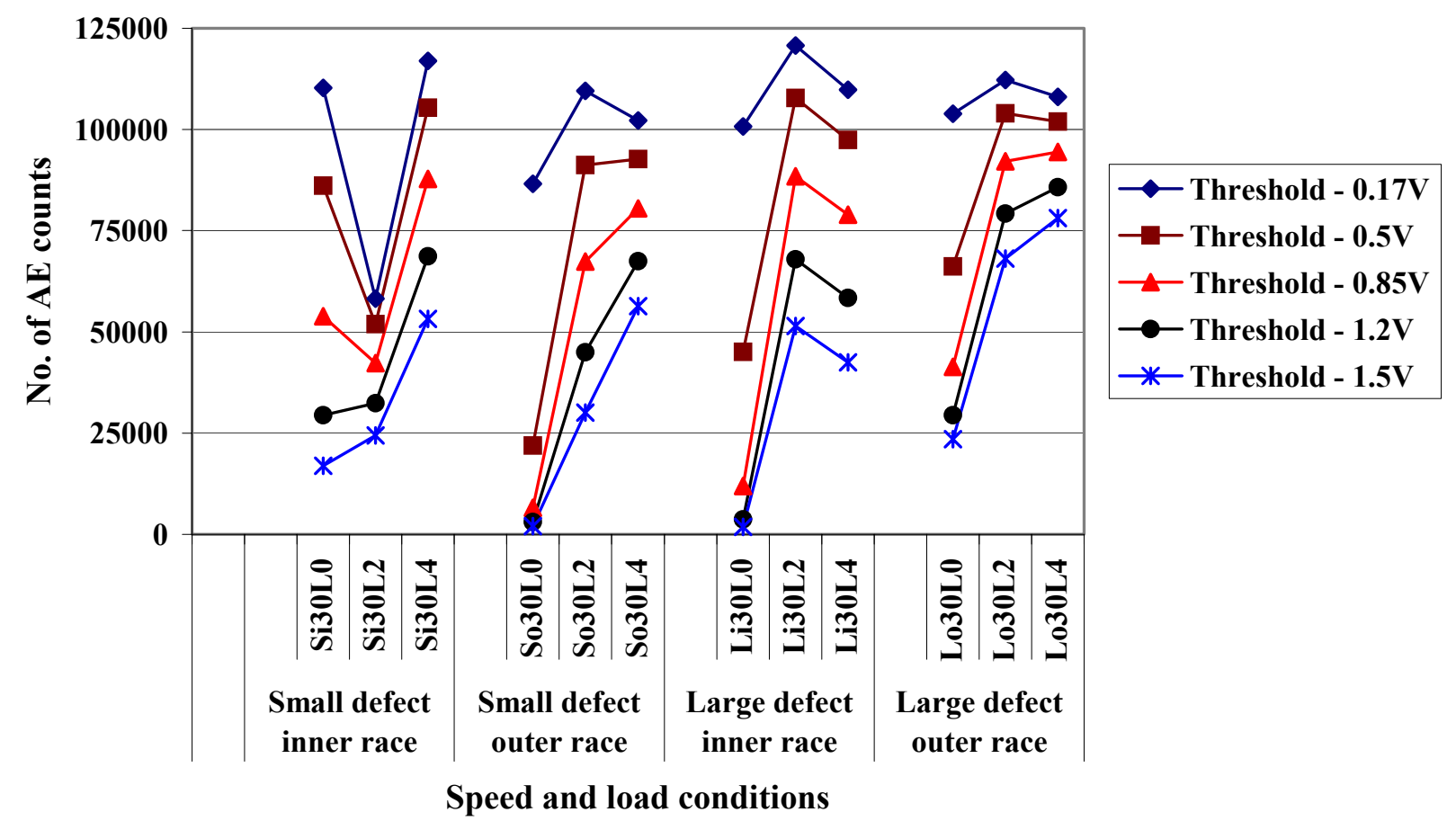

Figures 20 Number of AE counts for varying defects at 3000 rpm 
For all speed cases on outer race defects, there was a clear trend of increasing counts with load, irrespective of the threshold level. This did not hold true for all inner race defects.

\subsection{Results of AE counts with varying speed}

Figure 21 illustrates the relationship between AE counts and speed for a 'large' outer race defect. For fixed loads, increasing the rotational speed resulted in an increase in AE counts irrespective of threshold level. This was observed for all defect cases. However, at a threshold level of $0.17 \mathrm{~V}$ for load conditions 'L2' and 'L4', the above mentioned trend did not hold true. These results were similar for simulations on the 'large' inner race defect condition, see figure 22.

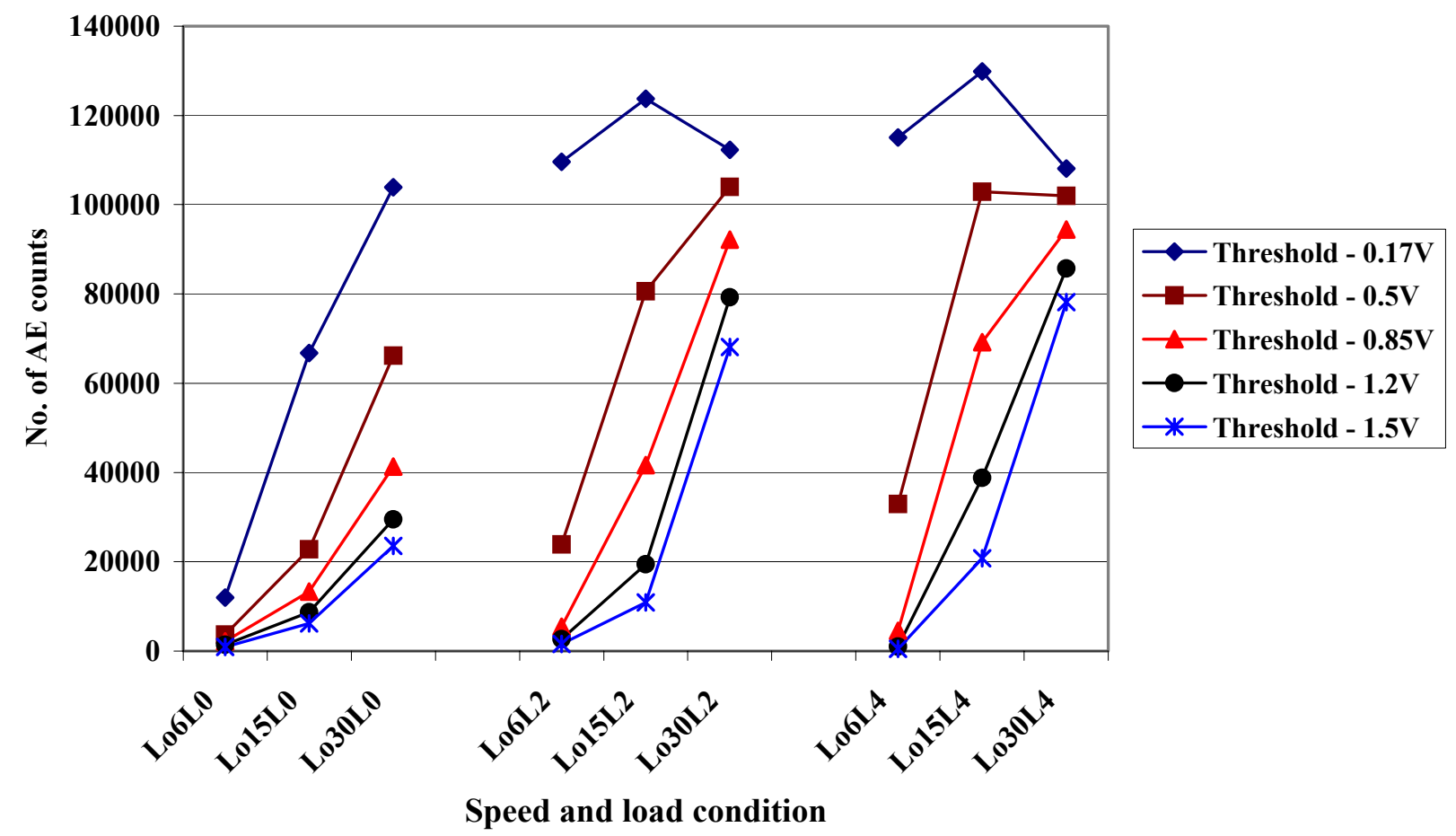

Figures 21 Number of AE counts for a 'large' outer race defect at varying speeds and load conditions 


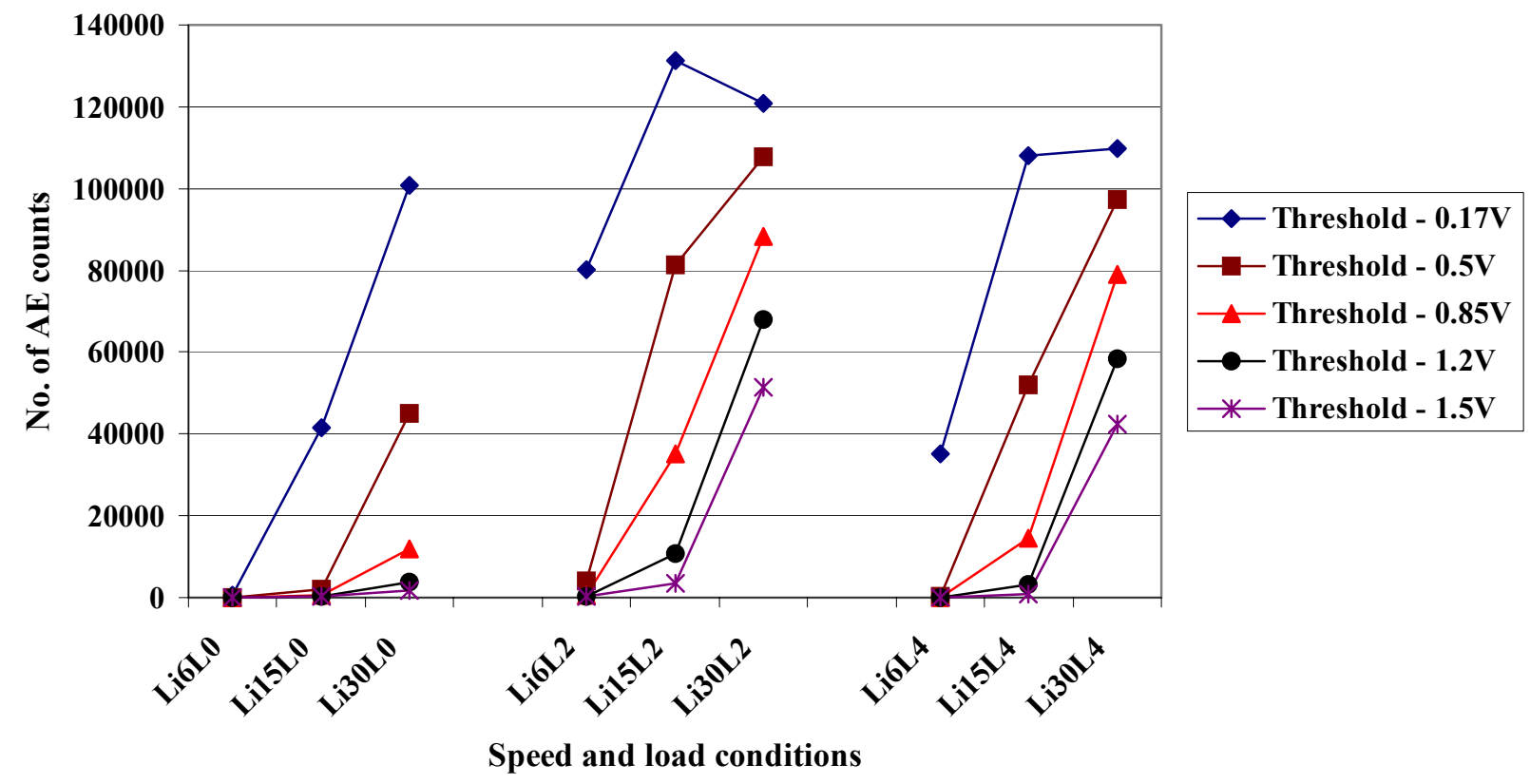

Figures 22 Number of AE counts for a 'large' inner race defect at varying speeds and load conditions

\subsection{Results of $\mathrm{AE}$ counts with varying defect size}

The relationship between counts, load and defect size at 1500rpm is depicted in figures 23 and 24. Apart from two cases (speed 1500rpm, load 2.4KN, trigger level 0.17 and 0.5 volts), for most outer race defects there was an increase in $\mathrm{AE}$ counts with increasing defect size. However, this did not hold true for inner race defects, see figure 24 . 


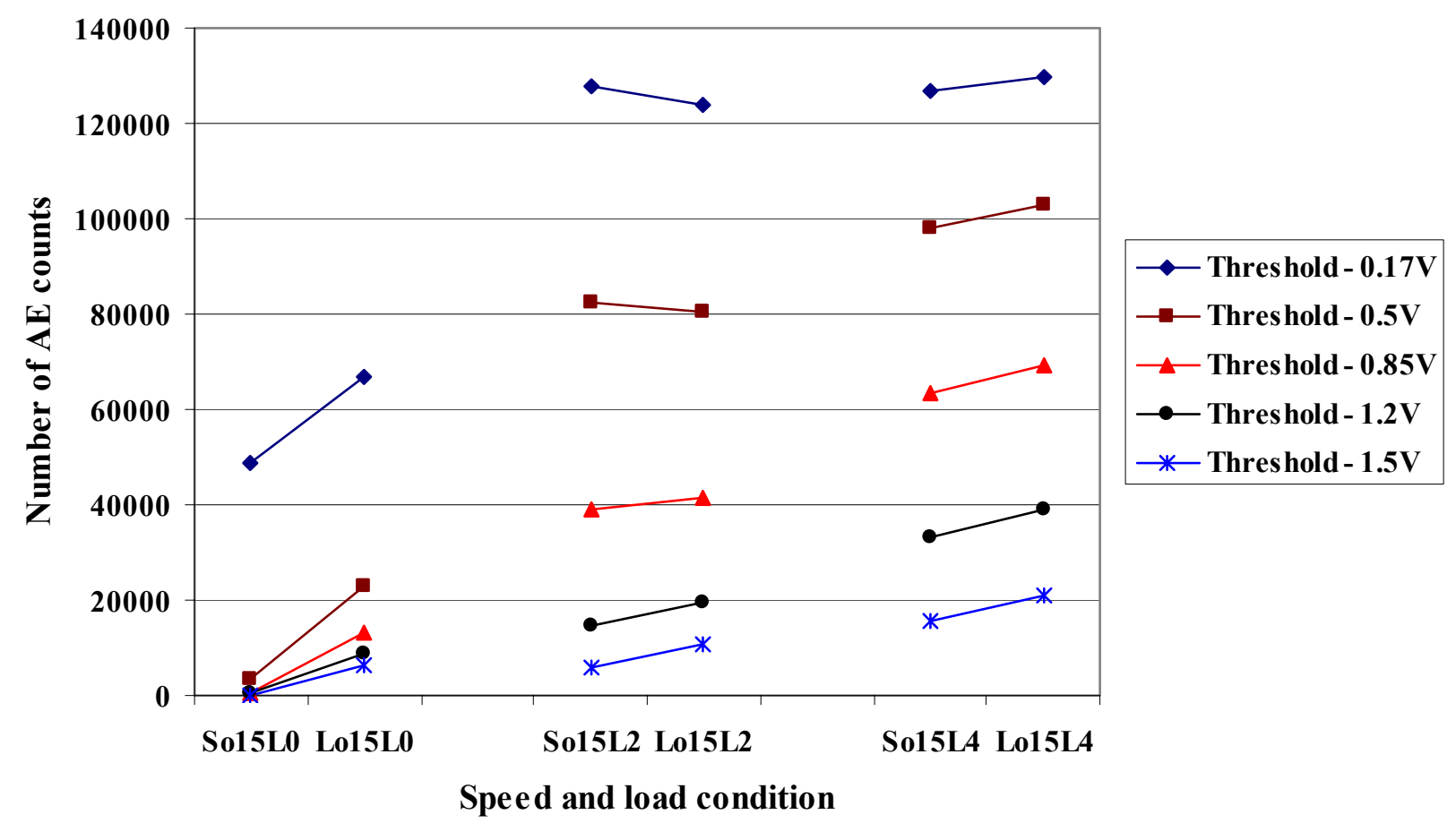

Figures 23 Number of AE counts for a varying outer race defect sizes at

\section{0rpm}

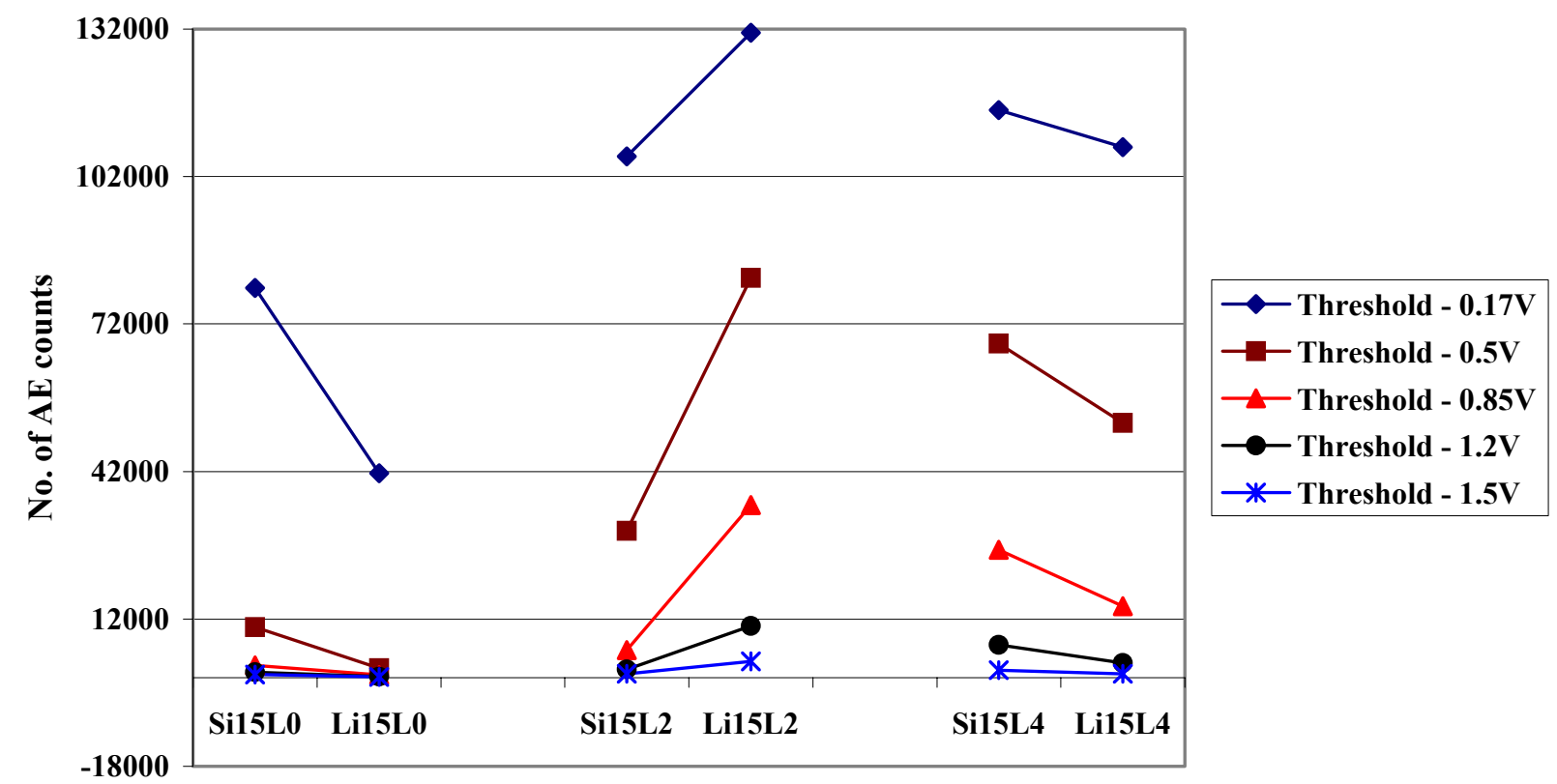

Speed and load conditions

Figures 24 Number of AE counts for a varying inner race defect sizes at 1500rpm 


\section{DISCUSION}

Background results clearly indicated a rise in r.m.s, peak amplitude and energy values with increasing rotational speed, this also applied to seeded defects. In addition, at

fixed rotational speeds there was evidence to suggest that increasing the load on the defect also resulted in an increase in r.m.s and energy values. This was particularly the case for both 'small' and 'large' outer race defects. On inner race defect simulations, the same trend was observed for the 'small' defect only. For 'large' inner race defects there was an increase in r.m.s value from $0 \mathrm{KN}$ to either 2.4 or $4.8 \mathrm{KN}$, see figure 16 . For fixed speeds and loads, increasing the defect size resulted in an increase in r.m.s value for outer race defects only. It was interesting to note that values of maximum amplitude did not increase with increasing load though an increase in rotational speed resulted in an increase in AE maximum amplitude.

Comparing r.m.s values of background noise with defect conditions, see figure 25 , it was evident that r.m.s values for defect conditions at a fixed speed were greater than values associated with background noise at the same speed. This was also observed for maximum amplitude and energy values. However for all inner race defects at $0 \mathrm{KN}$, the corresponding r.m.s values were undistinguishable from background noise levels. Furthermore, the results showed that background noise at high rotational speeds could mask defect signatures at lower operational speeds irrespective of the AE parameter measured, r.m.s, energy or amplitude. Therefore, in application of AE to bearing diagnosis, particularly on machinery operated over a range of speed conditions, it would be advisable to investigate background noise at all operational speeds. 


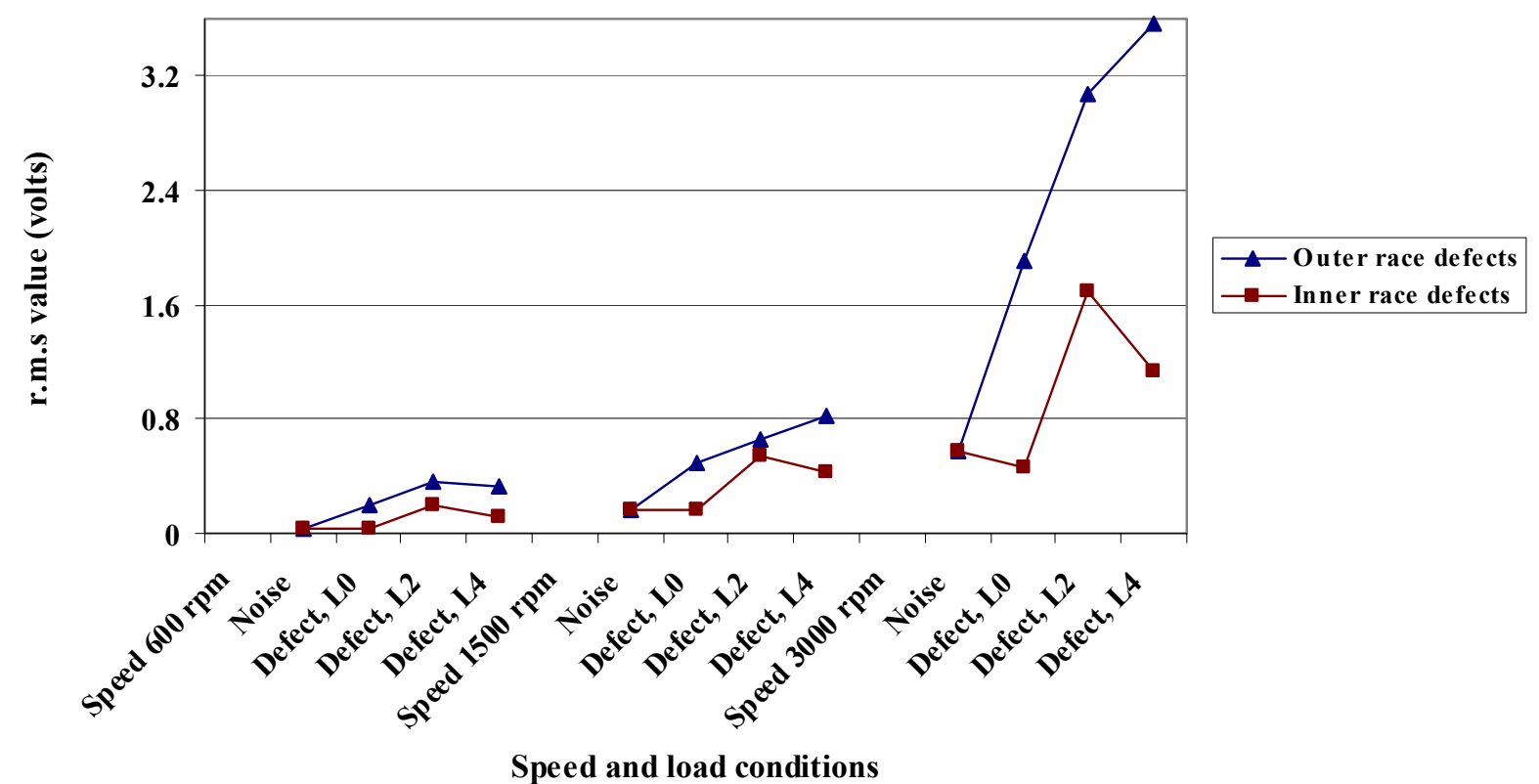

Figures 25 Background noise and 'large' defect AE r.m.s values for varying speed and load conditions

An increase in AE counts with defect size, load and speed was more evident for outer race defects. This very evident proportionality was also observed for r.m.s and energy values and probably explains why most reported successful experiments on the applications of $\mathrm{AE}$ to bearing diagnosis have been undertake on the outer race. In addition, it suggested that an attenuation of just $12 \mathrm{~dB}$ and $3 \mathrm{~dB}$ (for r.m.s and maximum amplitude values respectively, see appendix A) on inner race defect signatures may limit the extent of applicability of AE to monitoring changes in bearing operating condition of inner races. This phenomenon will probably always hold true irrespective of bearing size as the attenuation on bearing components will be more dependent on component interfaces than the geometric size. However, it must be noted that the applicability of AE to inner race defect analysis is also dependent on the strength of the AE source. 


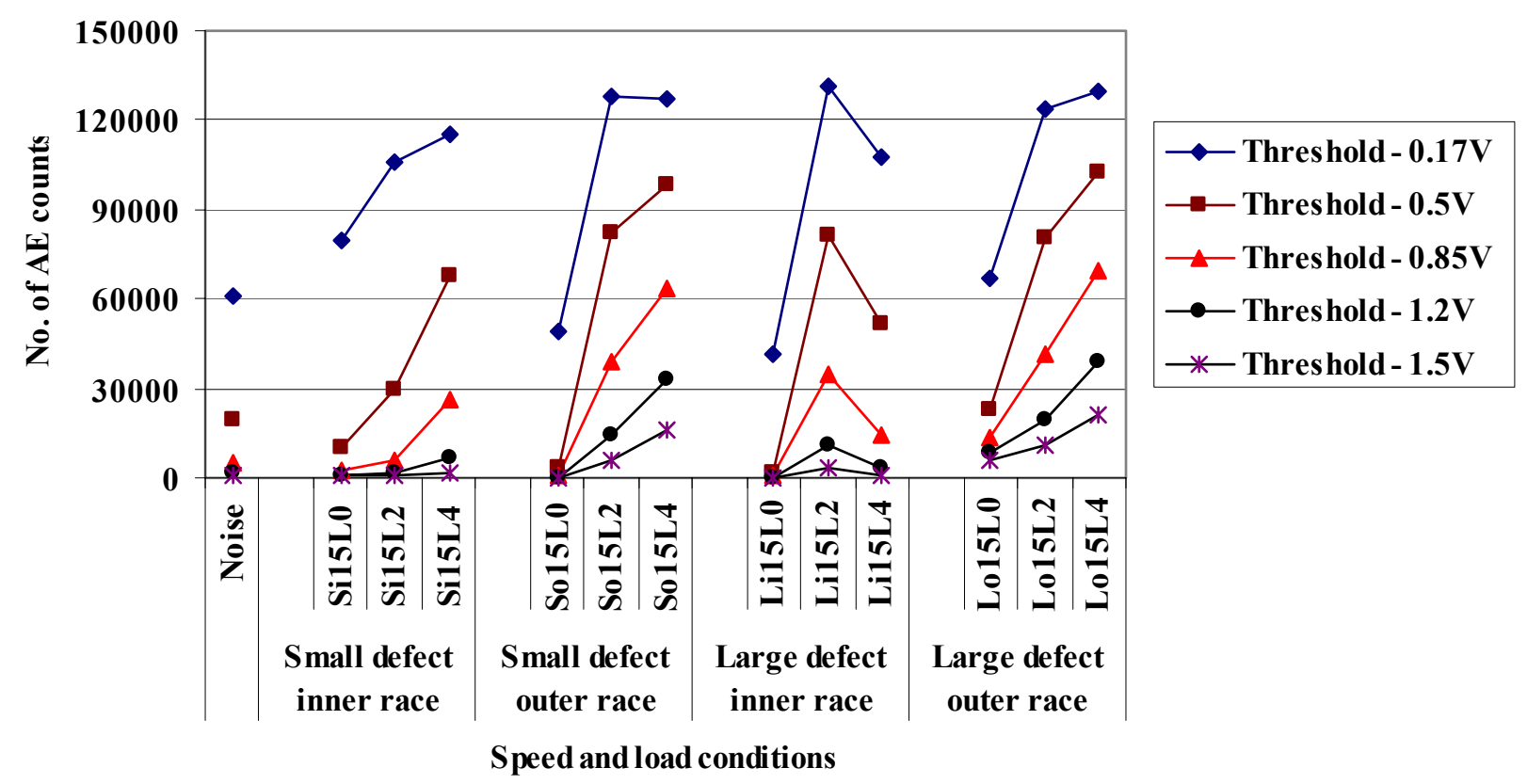

Figures 26 Background noise and defect AE counts for varying load and defects conditions; speed 1500 rpm

Comparing AE counts of background noise with defect conditions it was noted that inner and outer race defect count values were greater than background noise levels for load conditions above $0 \mathrm{KN}$, see figure 26. As observed with r.m.s values, background noise AE count at higher rotational speeds could mask defect conditions at lower speeds. For selection of the most appropriate threshold level it would be advisable, based on observations of this investigation, to select a threshold level at or above $30 \%$ of the maximum background amplitude for the lowest speed and load operating condition. AE threshold levels at or above this percentage value have been shown to provide direct correlation with defect size, load and speed, particularly for outer race defects. For some cases considered, for instance, 'large' outer race defect at varying speed and load conditions, a threshold level of less than $30 \%$ showed trends different from all other threshold levels, see figure 21. 


\section{CONCLUSION}

The use of r.m.s and count values has been validated as a robust technique for detecting bearing damage. Parameters such as r.m.s and energy have been shown to correlate with increasing speed, load and defect size. Values of AE maximum amplitude did correlate with increasing speed but not with load and defect size. In addition, it has been shown that the relationship between bearing mechanical integrity and AE counts is independent of the chosen threshold level, although a threshold of at least $30 \%$ of the lowest speed and load operating condition is advised. The application of $\mathrm{AE}$ to bearing defect diagnosis in this investigation showed more success in monitoring the condition on the outer race. Unlike the results reported by Tandon $\&$ Nakra [12] it was observed that AE counts could be used for defect size detection for lengths of up to $15 \mathrm{~mm}$ and widths of $1 \mathrm{~mm}$. In addition, the observations of Choudhary et al [13] were validated. It may be concluded that there isn't an ideal threshold that can be applied for analysis over all operating conditions. Therefore, in application of $\mathrm{AE}$ to bearing diagnosis, particularly on machinery operated over a range of speed conditions, it would be advisable to investigate background noise at all process operational speeds.

It is interesting to note that both r.m.s and $\mathrm{AE}$ count values could not distinguish between 'large' and 'small' defects on the inner race, though other operational changes such as increases in load had direct effects on the AE parameters. Although this investigation centered on a bearing with a rotating inner race, the authors believe that the results presented would be applicable to a rotating outer race with a stationary inner race. Whilst numerous exotic diagnostic techniques such as wavelets, higher 
order statistics, neural networks, etc, could be employed to aid diagnosis, all attempts must be made to keep the method of diagnosis simple and robust as this is the only way to encourage the adoption of this invaluable technique.

\section{REFERENCES}

1 Pao, Y-H., Gajewski, R.R. and Ceranoglu, A.N. (1979), Acoustic emission and transient waves in an elastic plate, J. Acoust. Soc. Am., 1979, 65(1), $96-$ 102.

2 Pollock AA, Acoustic Emission Inspection, Physical Acoustics Corporation, Technical Report, 1989, TR-103-96-12/89.

3 Mathews, J. R. Acoustic emission, Gordon and Breach Science Publishers Inc., New York. 1983, ISSN 0730-7152

4 Catlin Jr., J.B. The Use of ultrasonic diagnostic technique to detect rolling element bearing defects. Proceeding of Machinery and Vibration Monitoring and Analysis Meeting, Vibration Institute, USA, April 1983, 123-130.

5 Roger, L. M., The application of vibration analysis and acoustic emission source location to on-line condition monitoring of anti-friction bearings. Tribology International, 1979; 51-59.

6 Yoshioka T, Fujiwara T. New acoustic emission source locating system for the study of rolling contact fatigue, Wear, 81(1), 183-186.

7 Yoshioka T, Fujiwara T. Application of acoustic emission technique to detection of rolling bearing failure, American Society of Mechanical 
Engineers, Production Engineering Division publication PED, 1984, 14, $55-76$.

8 Hawman, M. W., Galinaitis, W. S, Acoustic Emission monitoring of rolling element bearings, Proceedings of the IEEE, Ultrasonics symposium, 1988, 885-889

9 Holroyd, T.J. and Randall, N., (1993), Use of Acoustic Emission for Machine Condition Monitoring, British Journal of Non-Destructive Testing, 1993, 35(2), 75-78.

10 Holroyd, T. Condition monitoring of very slowly rotating machinery using AE techniques. 14th International congress on Condition monitoring and Diagnostic engineering management (COMADEM'2001), Manchester, UK, 46 September 2001, 29, ISBN 0080440363

11 Bagnoli, S., Capitani, R. and Citti, P. Comparison of accelerometer and acoustic emission signals as diagnostic tools in assessing bearing. Proceedings of 2nd International Conference on Condition Monitoring, London, UK, May $1988,117-125$.

12 Tandon, N. and Nakra, B.C, Defect Detection of Rolling Element Bearings by Acoustic Emission Method, Journal of Acoustic Emission, 1990; 9(1) 25-28.

13 Choundhury, A. and Tandon, N., Application of acoustic emission technique for the detection of defects in rolling element bearings, Tribology International, 2000; 33, 39-45

14 Vibha Bansal, Gupta, B.C, Arun Prakash, Eshwar, V. A, Quality inspection of rolling element bearing using acoustic emission technique, 1990, Journal of Acoustic emission, 9(2), 142-146. 
15 Tan, C.C. Application of acoustic emission to the detection of bearing failures. The Institution of Engineers Australia, Tribology conference, Brisbane, 3-5 December 1990, 110-114.

16 Huguet, S, Godin, N, Gaertner, R, Salmon, L, Villard, D. Use of acoustic emission to identify damage modes in glass fibre reinforced polyester. Composites Science and Technology, 2002, 62, 1433-1444.

17 Miettinen J, Andersson, P. Acoustic emission of rolling bearings lubricated with contaminated grease, Tribology International, 2000, 33(11), 743-802

18 Mba, D., Bannister, R.H., and Findlay, G.E. Condition monitoring of lowspeed rotating machinery using stress waves: Part's I and II. Proceedings of the Instn Mech Engr 1999; 213(E): 153-185

19 N. Jamaludin, Dr. D. Mba, Dr. R. H. Bannister Condition monitoring of slowspeed rolling element bearings using stress waves. Journal of Process Mechanical Engineering, I Mech E. Pro. Inst. Mech Eng., 2001, 215(E):, Issue E4, 245-271.

20 Olli Yli-Harja, Medial Filters: Extensions, Anaylsis and Design. Lappeenrannan Research Papers, Paper 13, 1989. 


\begin{tabular}{|c|c|c|c|c|c|c|}
\hline Position & $\begin{array}{l}\text { Load } \\
(\mathrm{KN})\end{array}$ & Bearing element & $\begin{array}{l}\text { r.m.s } \\
\text { (Volts) }\end{array}$ & $\begin{array}{l}\text { Attenuation } \\
\text { (dB) }\end{array}$ & $\begin{array}{c}\text { Max } \\
\text { (Volts) }\end{array}$ & $\begin{array}{l}\text { Attenuation } \\
\text { (dB) }\end{array}$ \\
\hline B0T1 & 0 & Top bearing casing, close to the AE receiving sensor & 0.93 & & 9.41 & \\
\hline B0T2 & 0 & Outer race at 90 degree from top dead center & 0.56 & -4.49 & 9.44 & 0.02 \\
\hline B0T3 & 0 & Roller at Bottom Dead Center & 0.03 & -29.64 & 1.64 & -15.18 \\
\hline B0T4 & 0 & Inner race at Bottom Dead Center & 0.23 & -12.07 & 6.59 & -3.10 \\
\hline B3T1 & 3.5 & Top bearing casing, close to the AE receiving sensor & 0.59 & & 9.52 & \\
\hline B3T2 & 3.5 & Outer race at 90 degree from top dead center & 0.50 & -1.38 & 9.51 & -0.01 \\
\hline B3T3 & 3.5 & Roller at Bottom Dead Center & 0.02 & -30.42 & 0.79 & -21.66 \\
\hline B3T4 & 3.5 & Inner race at Bottom Dead Center & 0.20 & -9.44 & 6.14 & -3.81 \\
\hline B6T1 & 7 & Top bearing casing, close to the AE receiving sensor & 0.41 & & 9.50 & \\
\hline B6T2 & 7 & Outer race at 90 degree from top dead center & 0.48 & 1.44 & 9.54 & 0.03 \\
\hline B6T3 & 7 & Roller at Bottom Dead Center & 0.01 & -31.94 & 1.94 & -13.79 \\
\hline B6T4 & 7 & Inner race at Bottom Dead Center & 0.09 & -13.42 & 2.86 & -10.42 \\
\hline
\end{tabular}




\begin{tabular}{|c|c|c|c|}
\cline { 2 - 4 } \multicolumn{1}{c|}{} & \multicolumn{3}{c|}{ Outer race } \\
Small Defect \\
\hline \multicolumn{1}{c|}{ Condition } & \multicolumn{3}{c|}{} \\
\cline { 2 - 4 } & O6L0 & O6L2 & O6L4 \\
\hline r.m.s (volts) & 0.03 & 0.24 & 0.28 \\
\hline Max. amplitude (V) & 1.21 & 4.22 & 6.69 \\
\hline Energy (Vseconds) & 0.02 & 0.15 & 0.17 \\
\hline
\end{tabular}

\begin{tabular}{|c|c|c|}
\hline \multicolumn{3}{|c|}{ Outer race } \\
Small Defect \\
\hline O15L0 & O15L2 & O15L4 \\
\hline 0.17 & 0.60 & 0.74 \\
\hline 6.76 & 7.05 & 7.00 \\
\hline 0.10 & 0.36 & 0.46 \\
\hline
\end{tabular}

\begin{tabular}{|c|c|c|}
\hline \multicolumn{3}{|c|}{ Outer race } \\
Small Defect \\
\hline O30L0 & O30L2 & O30L4 \\
\hline 0.58 & 1.46 & 2.09 \\
\hline 24.80 & 32.03 & 31.88 \\
\hline 0.21 & 0.66 & 0.96 \\
\hline
\end{tabular}

\begin{tabular}{|c|c|c|c|}
\cline { 2 - 4 } \multicolumn{1}{c|}{} & \multicolumn{3}{c|}{ Outer race } \\
\multicolumn{1}{c|}{ Large Defect } \\
\hline Condition & \multicolumn{3}{c|}{} \\
\cline { 2 - 4 } & O6L0 & O6L2 & O6L4 \\
\hline r.m.s (volts) & 0.20 & 0.37 & 0.32 \\
\hline Max. amplitude (V) & 6.61 & 6.56 & 6.35 \\
\hline Energy (Vseconds) & 0.06 & 0.20 & 0.21 \\
\hline
\end{tabular}

\begin{tabular}{|c|c|c|}
\hline \multicolumn{3}{|c|}{ Outer race } \\
Large Defect \\
\hline O15L0 & O15L2 & O15L4 \\
\hline 0.50 & 0.65 & 0.82 \\
\hline 7.29 & 7.25 & 7.79 \\
\hline 0.21 & 0.40 & 0.51 \\
\hline
\end{tabular}

\begin{tabular}{|c|c|c|}
\hline \multicolumn{3}{|c|}{ Outer race } \\
Large Defect \\
\hline O30L0 & O30L2 & O30L4 \\
\hline 1.91 & 3.07 & 3.56 \\
\hline 34.77 & 53.76 & 40.72 \\
\hline 0.71 & 1.51 & 1.79 \\
\hline
\end{tabular}




\begin{tabular}{|c|c|c|c|}
\cline { 2 - 4 } \multicolumn{1}{c|}{} & \multicolumn{3}{c|}{ Inner race } \\
\multicolumn{1}{c|}{ Condition } & \multicolumn{3}{c|}{ Small Defect } \\
\cline { 2 - 4 } & I6L0 & I6L2 & I6L4 \\
\hline r.m.s (volts) & 0.04 & 0.11 & 0.18 \\
\hline Max. amplitude (V) & 1.59 & 1.09 & 1.25 \\
\hline Energy (Vseconds) & 0.02 & 0.07 & 0.12 \\
\hline
\end{tabular}

\begin{tabular}{|c|c|c|}
\hline \multicolumn{3}{|c|}{ Inner race } \\
Small Defect \\
\hline I15L0 & I15L2 & I15L4 \\
\hline 0.26 & 0.33 & 0.50 \\
\hline 4.80 & 4.87 & 5.90 \\
\hline 0.15 & 0.21 & 0.32 \\
\hline
\end{tabular}

\begin{tabular}{|c|c|c|}
\hline \multicolumn{3}{|c|}{ Inner race } \\
Small Defect \\
\hline I30L0 & I30L2 & I30L4 \\
\hline 0.83 & 1.35 & 1.36 \\
\hline 18.07 & 22.41 & 21.68 \\
\hline 0.51 & 0.40 & 0.83 \\
\hline
\end{tabular}

\begin{tabular}{|c|c|c|c|}
\cline { 2 - 4 } \multicolumn{1}{c|}{} & \multicolumn{3}{c|}{ Inner race } \\
Large Defect \\
\hline Condition & I6L0 & I6L2 & I6L4 \\
\cline { 2 - 4 } & 0.03 & 0.20 & 0.12 \\
\hline r.m.s (volts) & 1.32 & 6.04 & 2.51 \\
\hline Max. amplitude (V) & & 0.12 & 0.07 \\
\hline
\end{tabular}

\begin{tabular}{|c|c|c|}
\hline \multicolumn{3}{|c|}{ Inner race } \\
Large Defect \\
\hline I15L0 & I15L2 & I15L4 \\
\hline 0.16 & 0.54 & 0.42 \\
\hline 4.06 & 6.92 & 6.20 \\
\hline 0.09 & 0.34 & 0.27 \\
\hline
\end{tabular}

\begin{tabular}{|c|c|c|}
\hline \multicolumn{3}{|c|}{ Inner race } \\
Large Defect \\
\hline I30L0 & I30L2 & I30L4 \\
\hline 0.46 & 1.69 & 1.14 \\
\hline 12.01 & 32.47 & 13.14 \\
\hline 0.27 & 0.82 & 0.70 \\
\hline
\end{tabular}




\begin{tabular}{|c|c|c|c|c|c|}
\hline Threshold & $0.17 \mathrm{~V}$ & $0.5 \mathrm{~V}$ & $0.85 \mathrm{~V}$ & $1.2 \mathrm{~V}$ & $1.5 \mathrm{~V}$ \\
\hline \multicolumn{6}{|c|}{ Small defect inner race } \\
\hline Si6L0 & 1023 & 61 & 11 & 2 & 1 \\
\hline Si6L2 & 28427 & 83 & 4 & 0 & 0 \\
\hline Si6L4 & 74926 & 2769 & 26 & 0 & 0 \\
\hline Si15LO & 79355 & 10332 & 2594 & 1149 & 654 \\
\hline Si15L2 & 106143 & 29951 & 5671 & 1725 & 837 \\
\hline Si15L4 & 115564 & 67996 & 26077 & 6710 & 1573 \\
\hline Si30LO & 110307 & 86110 & 53857 & 29422 & 16957 \\
\hline Si30L2 & 58178 & 51921 & 42326 & 32344 & 24405 \\
\hline Si30L4 & 116960 & 105339 & 87777 & 68616 & 53236 \\
\hline \multicolumn{6}{|c|}{ Small defect outer race } \\
\hline So6L0 & 457 & 26 & 3 & 0 & 0 \\
\hline So6L2 & 95223 & 10190 & 511 & 163 & 88 \\
\hline So6L4 & 100412 & 19436 & 1370 & 269 & 159 \\
\hline So15L0 & 48986 & 3173 & 720 & 323 & 185 \\
\hline So15L2 & 128034 & 82625 & 39008 & 14561 & 5979 \\
\hline So15L4 & 126982 & 98249 & 63587 & 32993 & 15731 \\
\hline So30L0 & 86598 & 21926 & 6580 & 3064 & 2038 \\
\hline So30L2 & 109524 & 91259 & 67363 & 44976 & 30114 \\
\hline So30L4 & 102280 & 92737 & 80527 & 67445 & 56346 \\
\hline \multicolumn{6}{|c|}{ Large defect inner race } \\
\hline Li6L0 & 664 & 26 & 7 & 1 & 0 \\
\hline Li6L2 & 80259 & 4110 & 506 & 273 & 165 \\
\hline Li6L4 & 35094 & 290 & 91 & 42 & 23 \\
\hline Li15L0 & 41644 & 2021 & 614 & 278 & 146 \\
\hline Li15L2 & 131246 & 81370 & 35131 & 10616 & 3405 \\
\hline Li15L4 & 107958 & 51879 & 14567 & 3080 & 877 \\
\hline Li30L0 & 100787 & 45093 & 11911 & 3666 & 1817 \\
\hline Li30L2 & 120727 & 107753 & 88424 & 67938 & 51465 \\
\hline Li30L4 & 109847 & 97439 & 78909 & 58368 & 42446 \\
\hline
\end{tabular}




\begin{tabular}{|c|c|c|c|c|c|}
\hline Threshold & $\mathbf{0 . 1 7 V}$ & $\mathbf{0 . 5 V}$ & $\mathbf{0 . 8 5 V}$ & $\mathbf{1 . 2 V}$ & $\mathbf{1 . 5 V}$ \\
\hline Large defect outer race & & & & & \\
\cline { 1 - 6 } Lo6L0 & 11982 & 3709 & 2212 & 1384 & 893 \\
\hline Lo6L2 & 109572 & 23877 & 5406 & 2665 & 1555 \\
\hline Lo6L4 & 115029 & 32891 & 4493 & 1001 & 488 \\
\hline Lo15L0 & 66748 & 22769 & 13285 & 8718 & 6204 \\
\hline Lo15L2 & 123725 & 80590 & 41665 & 19479 & 10913 \\
\hline Lo15L4 & 129826 & 102848 & 69208 & 38831 & 20784 \\
\hline Lo30L0 & 103876 & 66190 & 41319 & 29463 & 23519 \\
\hline Lo30L2 & 112255 & 103959 & 92197 & 79235 & 68133 \\
\hline Lo30L4 & 108083 & 101972 & 94424 & 85735 & 78127 \\
\hline
\end{tabular}

